\title{
Milk saturated fatty acids, odd- and branched-chain fatty acids, and isomers of C18:1, C18:2, and C18:3n-3 according to their duodenal flows in dairy cows: A meta-analysis approach
}

\author{
L. A. Prado, ${ }^{1}$ Ph. Schmidely, ${ }^{2}$ P. Nozière, ${ }^{1}$ and A. Ferlay ${ }^{1 *}$ \\ ${ }^{1}$ INRA, VetAgro Sup, UMR Herbivores, Université Clermont Auvergne, F-63122 Saint-Genès-Champanelle, France \\ ${ }^{2}$ INRA, UMR0791 Mosar, AgroParisTech, 16 rue Claude Bernard, F-75231 Paris, France
}

\section{ABSTRACT}

We sought to establish predictive response models of milk fatty acid (FA) yields or concentrations from their respective duodenal flow, rumen digestive parameters, or diet characteristics in dairy cows, with a special focus on cis and trans isomers of C18:1, C18:2, odd- and branched FA, and mammary de novo synthesized FA. This meta-analysis was carried out using data from trials with nature of forage, percentage of concentrate, supplementation of diets with vegetable oils or seeds, and marine products' animal fats as experimental factors. The data set included 34 published papers representing 50 experiments with 142 treatments. Increasing duodenal C18 FA flow induced a quadratic increase in milk total $\mathrm{C} 18$ yield and a linear decrease in milk C4:0 to $\mathrm{C} 14: 0$ concentration. Intra-experimental predictive response models of individual milk cis $\mathrm{C} 18: 1$ isomers ( $\Delta 11$ to 15 position) from their respective duodenal flows had coefficients of determination $\left(\mathrm{R}^{2}\right)$ ranging from 0.74 to 0.99 , with root mean square error varying from 0.19 to $0.96 \mathrm{~g} / \mathrm{d}, 0.02$ to $0.10 \%$ of total FA, and 0.03 to $0.29 \%$ of $\mathrm{C} 18$ FA. Models predicting milk trans C18:1 isomer yields or concentrations had $\mathrm{R}^{2}$ greater than 0.90 (except for trans-4 and trans-10 C18:1) with root mean square error varying from less than 0.1 to $5.2 \mathrm{~g} / \mathrm{d}$. Linear regressions for C18:2n-6, trans-10, cis-12 CLA, and trans-11,trans-13 CLA were calculated according to their respective duodenal flows. Quadratic models of milk $\mathrm{C} 18: 3 \mathrm{n}-3$ yield or concentration from its duodenal flow had $\mathrm{R}^{2}$ values above 0.97 . Models of amounts desaturated from C18:0 into cis-9 C18:1 and trans-11 C18:1 into cis-9,trans-11 CLA indicated that the contribution of C18:0 and trans-11 C18:1 desaturation to respective cis-9 $\mathrm{C} 18: 1$ and cis-9,trans-11 CLA yields in milk fat was $83.8 \%( \pm 0.75)$ and $86.8 \%( \pm 2.8)$. Furthermore, when cows were fed marine products, our results could indicate a lower mammary uptake of

Received June 12, 2018.

Accepted December 10, 2018.

*Corresponding author: anne.ferlay@inra.fr
C18:0 and trans-11 C18:1 in proportion to their respective duodenal flow, with no associated change in mammary $\Delta^{9}$-desaturase activity. Yields or concentrations of $\mathrm{C} 15: 0, \mathrm{C} 17: 0$, iso-C15:0, iso-C17:0, anteiso-C15:0, and anteiso-C17:0 were dependent on their respective duodenal flow or concentration at duodenum, but synthesis of these FA from C3 units for linear-chain odd FA, and from C2 units for branched-chain FA was suggested, respectively. Several milk C18 FA concentrations were closely related to their duodenal concentrations with slopes of the linear models close to the bisector; this could reflect a priority for the use of these duodenal C18 FA by the mammary gland to favor their high concentration in plasma triglycerides and nonesterified FA, which are preferentially taken up by the mammary gland.

Key words: dairy cow, milk fatty acid, duodenal flow, lipid supplementation, meta-analysis

\section{INTRODUCTION}

Milk lipids in dairy cows are characterized by a high level of SFA and low level of UFA, especially n-3 fatty acids (FA), which reflects ruminal biohydrogenation of UFA and de novo mammary synthesis of SFA, despite the activity of mammary $\Delta^{9}$-desaturase (Chilliard et al., 2007). This profile of milk fat has often been criticized for human nutrition when compared with nutritional recommendations (ANSES, 2011), especially in what concerns their saturated and trans FA content. Consequently, several environmental (nutrition) and intrinsic factors (genetic selection) were studied to modify the profile of milk FA in cows (Ferlay et al., 2017).

Feeding practices are the most rapid and effective way to modulate milk FA composition in dairy females and several meta-analyses quantified the effect of different dietary factors on milk fat composition. However, most of these meta-analyses either focused on specific feeding systems (grass-based feeding systems, Elgersma, 2015), oilseed supplementation (Glasser et al., 2008a; Meignan et al., 2017), or on specific FA (C18:2n-6, C18: 3n-3, Khiaosa-Ard et al., 2015), and few attempts have 
been made to produce quantitative laws of responses of milk FA profile to interactions among feeding factors (Schmidely et al., 2018). However, these laws of responses are essential to quantify the milk FA profile in the feed systems encountered in practice, which often associate different dietary factors in combination. Improving quantification of these responses is a perspective of the renewed feed unit systems to manage milk FA content and profile according to dietary factors (INRA, 2018).

Recent feed unit systems are always more mechanistic and they separate the digestive processes from the transfer of absorbed nutrients into the mammary gland (INRA, 2018). However, this is not still the case for lipids in predicting a complete milk FA profile. At digestive level, several meta-analyses have predicted the flows of total duodenal FA and specific isomers of C18:1, C18:2n-6, and C18:3n-3 (Glasser et al., 2008c; Schmidely et al., 2008), and this has recently been revisited owing to the increased availability of data on biohydrogenation intermediates, and on some feeding factors as grazing or fish oils (Prado et al., 2018). The transfer of duodenal FA into milk (Glasser et al., 2008b) has been exclusively investigated during lipid supplementation and deals only with total FA with 18 atoms of carbon (C18) and some specific FA (total $\mathrm{C} 18: 3, \mathrm{C} 18: 2 \mathrm{n}-6$, and some trans isomers of $\mathrm{C} 18: 1$ ) with no information on CLA isomers, branched-chain FA, or SFA. However, the FA transfer calculated in Glasser et al. (2008b) included information using duodenal infusion of some FA over short periods, which may differ from the animal responses during feeding trials. Moreover, these data focused on lipid supplementation, which prevents extrapolation of these data to other dietary situations.

Consequently, the objectives of this study were to quantify through a meta-analysis approach the relationships between duodenal flows of FA and absorbed nutrients (VFA) on the one hand and FA secreted into milk on the other hand, including very different feeding strategies (grazing, lipid supplementation, and percentage of concentrate alone or in combination with other dietary factors) to connect these relationships with those established between FA intake and duodenal FA, to constitute a full set of equations to predict milk FA from dietary components.

\section{MATERIALS AND METHODS}

\section{Publications Selected and Characteristics of the Database}

We extracted from the AGRum database (IDDN. FR.001.510032.000.R.C.2011.000.10300) the trials studying the relationships between duodenal flows of FA and milk yield or proportion of FA in response to changes in dietary factors. The characteristics of the database and its statistical analysis have been previously described (Glasser et al., 2008c; Prado et al., 2018). Data from Sterk et al. (2012) that were erroneously omitted in Prado et al. (2018) were included in the present analysis (Supplemental Data; https://doi.org/10.3168/jds.2018-15194). Moreover, nonpublished duodenal flows of FA associated with the data of Ferlay et al. (2013) were provided by the authors and included in the actual data set. Trials studying lipid infusion in the duodenum or abomasum were not included because they often differ in duration compared with feeding trials, which may affect the response of milk fat secretion and FA profile. Consequently, we kept studies focusing on the effect of dietary factors (mainly lipid supplementation with vegetable oils or seeds, animal fats, fish oils, changes in percentage of concentrate, and nature of forage; see Prado et al., 2018) with a final data set including 35 published papers reporting 50 experiments (number of experiments, $\mathbf{N}_{\exp }$ ) with 142 treatments (number of treatments, $\mathbf{N}_{\text {trt }}$ ).

Some data were eliminated. Concerning the model of cis-13 C18:1, data from Sterk et al. (2012) were not considered because of aberrant values of duodenal flow of this FA. Concerning the milk C18:3n-3 model, one treatment (protected-linseed supplementation) of the same study was eliminated because of aberrant secretion of this FA in milk. Data from Loor et al. (2004) were not used for the model of trans-5 C18:1 because of aberrant values of its duodenal flow. We did not use the study of Chelikani et al. (2004) because of aberrant values of duodenal DM, ADF, and NDF flows. Moreover, in some cases, the flow of certain FA in milk was higher than that arising from the duodenum with no possible synthesis in the mammary gland (e.g., C18:3n-3 or C18: $2 n-6)$ or no contribution of adipose tissue mobilization as cows were in most cases in mid-lactation. This could be due to the relative uncertainty of measurement, which is assumed to be homogeneous between treatments of a given study; these data were consequently kept in the analysis.

Cows in the database were on average in mid-lactation (DIM $=108 \pm 5 \mathrm{~d}$, mean $\pm \mathrm{SE})$, with an average BW of $607 \pm 5 \mathrm{~kg}$, a mean milk production of $29 \pm 0.7$ $\mathrm{kg} / \mathrm{d}$, a mean fat yield of $0.98 \pm 0.02 \mathrm{~kg} / \mathrm{d}$, and a milk protein yield of $0.89 \pm 0.02 \mathrm{~kg} / \mathrm{d}$. Average daily DMI was $19.7 \pm 0.3 \mathrm{~kg}$ of $\mathrm{DM} / \mathrm{d}$, with a mean concentrate percentage of $47.0 \pm 1.0 \%$, and a mean $\mathrm{CP}$ content of $16.8 \pm 0.2 \% /$ DMI (Supplemental Tables S1 and S2; https://doi.org/10.3168/jds.2018-15194). 


\section{Calculations of Flows}

Total FA yield was calculated from the milk fat yield reported in the publications, assuming that total FA represents 0.93 of milk fat (Glasser et al., 2008b), and individual FA yield was calculated as its proportion in total FA multiplied by total FA yield. For publications directly reporting individual FA yield, these were recalculated with the same method to ensure consistency between trials. Contrary to the approach previously developed by Glasser et al. (2008b), we decided to develop specific equations relating individual milk FA yield $(\mathrm{g} / \mathrm{d})$ to respective flow in the duodenum $(\mathrm{g} / \mathrm{d})$ when sufficient data $\left(\mathrm{N}_{\text {trt }}>10\right)$ were available. No minimal threshold dealing with number of trials or number of published papers was fixed when a low number of treatments was available. We also developed equations that relates the proportion in milk fat (\% of total FA) to its concentration in the duodenum ( $\mathrm{g}$ of FA in duodenum $/ \mathrm{kg}$ of DMI) and for the isomers of C18:1, C18:2, and C18:3, we obtained relations between their percentage in milk (expressed as a \% of total milk C18 FA) and their percentage in the duodenum (\% of total duodenal C18 FA). When FA in milk do not have a corresponding flow at the duodenum (e.g., short- to medium-chain FA arising from mammary lipogenesis, some branched-chain FA), equations were developed from data characterizing rumen fermentation (ruminal acetate, butyrate, and propionate concentrations, $\mathrm{m} M$ ) or from dietary characteristics. Ruminal acetate and butyrate concentrations were preferred to VFA flows predicted using the new INRA feeding system (INRA, 2018) by the Systool.fr application (Chapoutot et al., 2015) because we chose to focus on measured rather than calculated data.

Mammary lipogenesis was considered to be represented by the sum of straight and even-chain FA having 4 to 14 atoms of carbon (in $\mathrm{g} / \mathrm{d}$ or as $\%$ of total FA), whereas even- and branched-chain FA were considered individually. Palmitic acid was highly related to the sum of C4:0 to C14:0 FA yield and moderately related to the proportion in total milk FA $(\mathrm{r}=0.75, P<$ 0.001 for milk yield, and $\mathrm{r}=0.25, P<0.005$ for milk concentration), reflecting the fact that it arises mainly from lipogenesis in our database. However, because numerous data for duodenal C16:0 flows were available, we predicted C16:0 in milk from its duodenal flow and not from ruminal acetate or butyrate concentrations. Apparent transfer of the sum of the substrate (SFA) and product of the $\Delta^{9}$-desaturase (cis-9 MUFA) was estimated for each treatment by the ratio between the sum of the substrate and product in milk yield $(\mathrm{g} / \mathrm{d})$ and the corresponding sum in the duodenum $(\mathrm{g} / \mathrm{d})$. The mammary uptake of substrates and products of desaturase was then calculated separately using the apparent transfer of the sum of the SFA and cis-9 MUFA applied to the duodenal flows of substrates and products. This estimate of mammary uptake of substrates was then deducted from their milk yields to provide an estimation of the quantity of desaturated FA as described by Glasser et al. (2008b). The contribution of the desaturase activity to the actual milk yield of cis-9 C18:1 and cis-9,trans-11 CLA was then calculated as the ratio between the production of that FA by desaturation divided by the actual yield of that FA.

\section{Statistical Analysis}

Because long-chain FA from marine products may affect de novo mammary lipogenesis and mammary $\Delta^{9}$-desaturase activity, the data set was split into 2 subsets: the first subset (fish) contained only control treatments, and treatment containing marine products, and the second forage/concentrate/lipids (FCL) subset with dietary treatments included the nature and proportions of forages, and percentage of concentrate and lipid supplementation as seeds, oils, or animal fats. For each subset, specific relationships relating duodenal flows or ruminal characteristics and milk FA were produced according to variance-covariance analysis (General Linear Models with Minitab, version 17, Minitab Inc., State College, PA) including the fixed effect of experiment and either the duodenal flow of the FA or the ruminal characteristics as covariates. Equations were derived for milk FA yields (g/d) or milk FA concentrations (\% of total milk FA, or percentage of total milk C18 FA).

\section{RESULTS}

\section{Milk Total C18 FA, Cis and Trans Isomers of C18:1, C18:2, and C18:3n-3}

The intra-experiment model of milk total C18 FA yield presented a linear effect and a quadratic effect of duodenal total C18 FA flow with a coefficient of determination $\left(\mathbf{R}^{2}\right)$ equal to 0.89 (Table 1 and Figure $1 \mathrm{~A}$ ) and a linear effect when milk C18 FA concentration (\% of total FA) was related to total duodenal C18 FA (g/ $\mathrm{kg}$ of DMI). Models of milk cis C18:1 isomers (from cis-11 to cis-15) calculated in 3 different units $(\mathrm{g} / \mathrm{d}, \%$ of total $\mathrm{C} 18 \mathrm{FA}, \%$ of total $\mathrm{FA}$ ) from their respective duodenal FA flows (Table 1 ) had an $\mathrm{R}^{2}$ between 0.74 and 0.99 .

The models of milk yields of cis-11, cis-12, and cis-13 C18:1 isomers were linear with slopes of $0.22 \pm 0.07$, $0.40 \pm 0.05$, and $0.40 \pm 0.08$, respectively. For these isomers, the linear models presented slopes varying from 0.24 to 1.03 when milk FA was expressed in percentage 
MILK FATTY ACIDS AND THEIR DUODENAL FLOWS

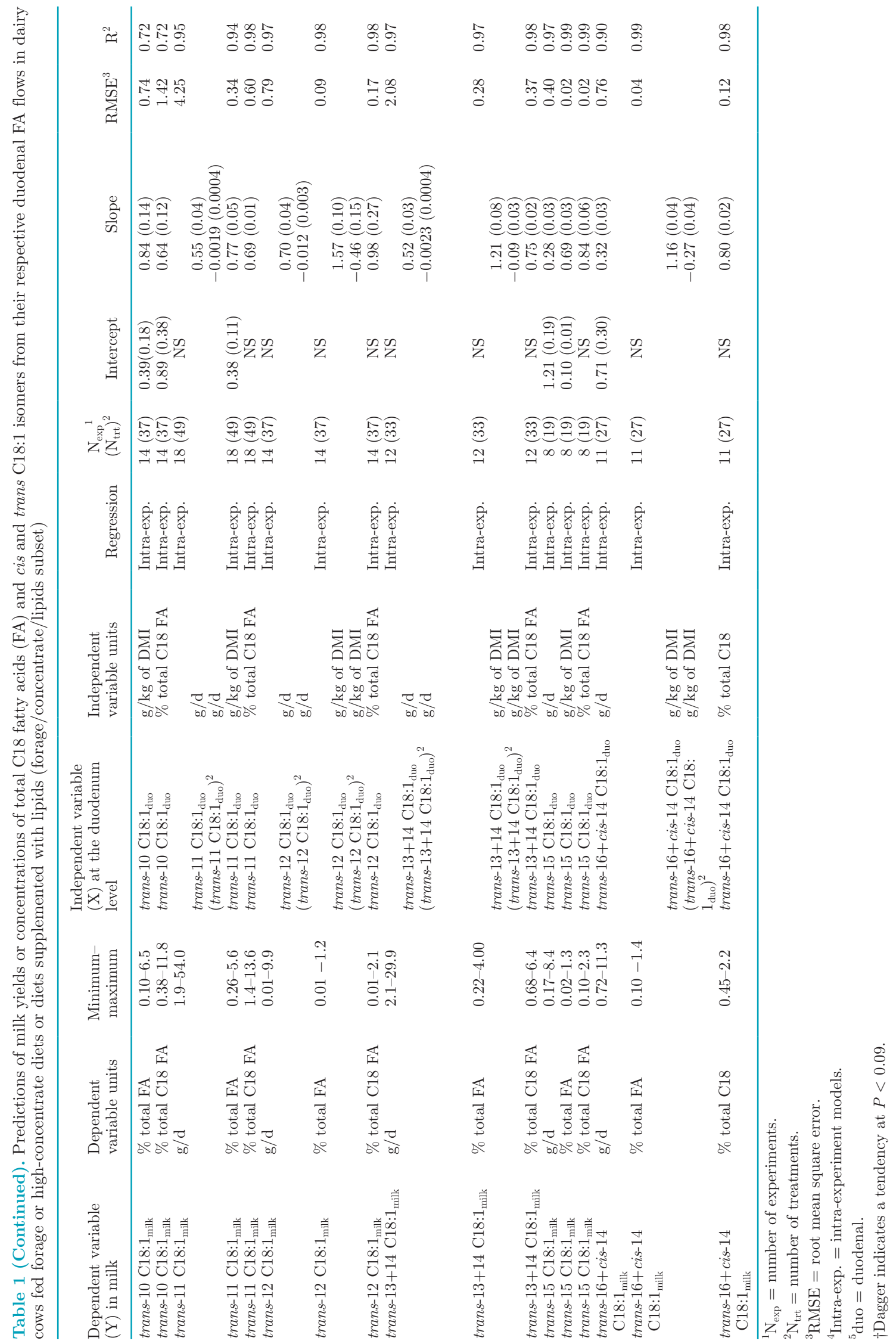



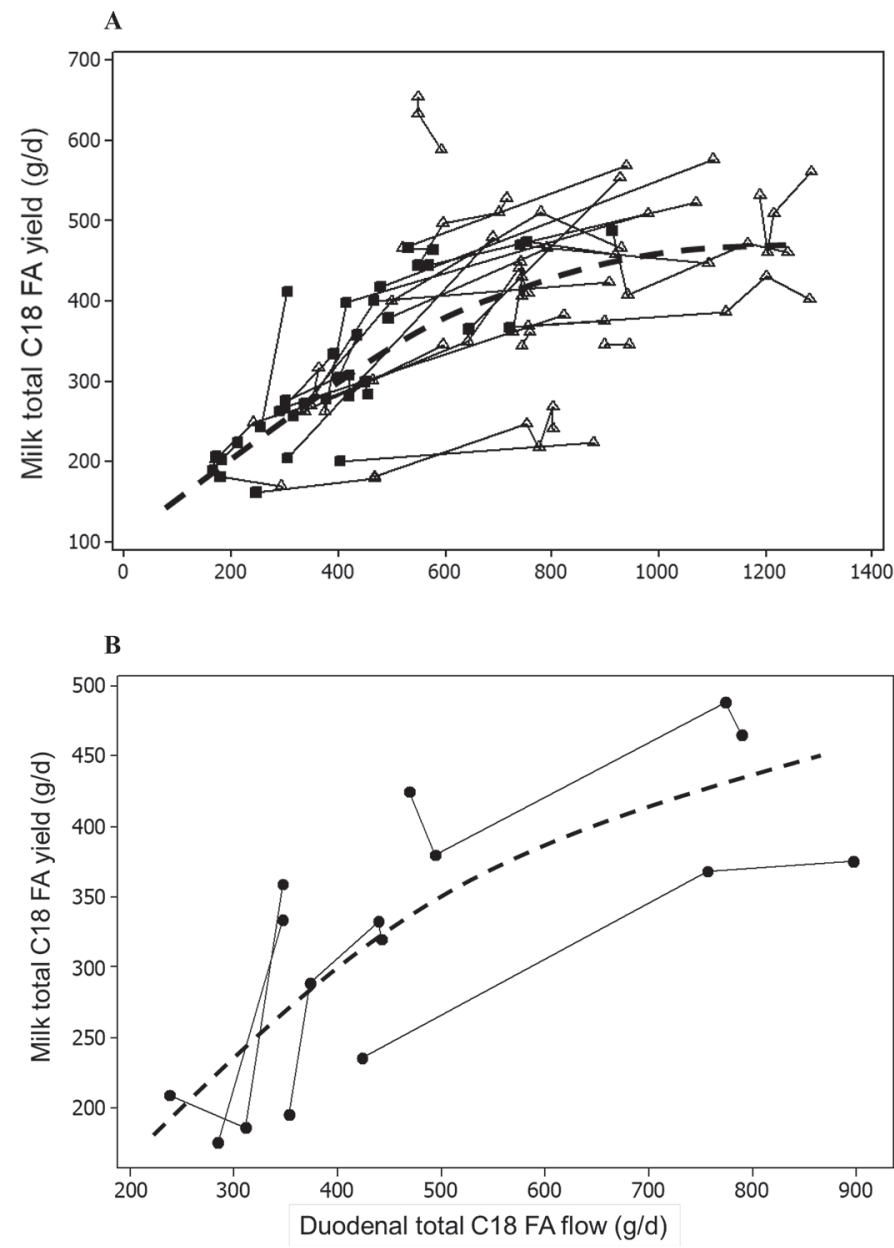

Figure 1. (A) Intra-experimental relationship between milk total C18 fatty acid (FA) yield (Y,g/d) and duodenal total C18 FA flow (X, $\mathrm{g} / \mathrm{d}$ ), where $(\Delta)$ are the lipid diets and $(\mathbf{\square})$ diets without lipid supplementation from the forage/concentrate/lipids subset. The dashed line (- - ) shows the quadratic fitted model $[\mathrm{Y}=97.1 \pm 36.4+0.66 \pm$ $0.11 \cdot \mathrm{X}-0.00029 \pm 0.00008 \cdot \mathrm{X}^{2}$, number of experiments $\left(\mathrm{N}_{\exp }\right)=35$, number of treatments $\left(\mathrm{N}_{\text {trt }}\right)=96$, root mean square error $(\mathrm{RMSE})=$ $\left.38.6 \mathrm{~g} / \mathrm{d}, \mathrm{R}^{2}=0.89\right]$. (B) Intra-experimental relationship between milk total C18 FA yield $(\mathrm{Y} \mathrm{g} / \mathrm{d})$ and duodenal total C18 FA flow $(\mathrm{X} \mathrm{g} / \mathrm{d})$ from the fish subset. The dashed line (- - ) shows the quadratic fitted model $\left(\mathrm{Y}=0.97 \pm 0.10 \cdot \mathrm{X}-0.0005 \pm 0.0002 \cdot \mathrm{X}^{2}, \mathrm{~N}_{\mathrm{exp}}=5, \mathrm{~N}_{\text {trt }}=16\right.$, $\left.\mathrm{RMSE}=51.2 \mathrm{~g} / \mathrm{d}, \mathrm{R}^{2}=0.98\right)$.

of total C18 FA. For the linear models expressed in percentage of total $\mathrm{FA}$, the slopes varied from 0.38 to 1.28 for cis-11- and cis-13 C18:1 isomers. The models of cis-12 (when expressed in \% of total FA), and cis-15 C18:1 (when expressed in $\mathrm{g} / \mathrm{d}, \%$ of total FA, or $\%$ of total C18 FA) showed an intra-experiment quadratic regression. In addition, the intercept was often significant for these different models, with the exception of cis-12 (\% of total C18 FA and \% of C18 FA) and cis-15 C18:1 (with the 3 units).

Figure 2 shows the relationship between milk C4: 0-C14:0 concentration and duodenal total C18 FA flow. Milk C4:0-C14:0 concentration decreased with increas-
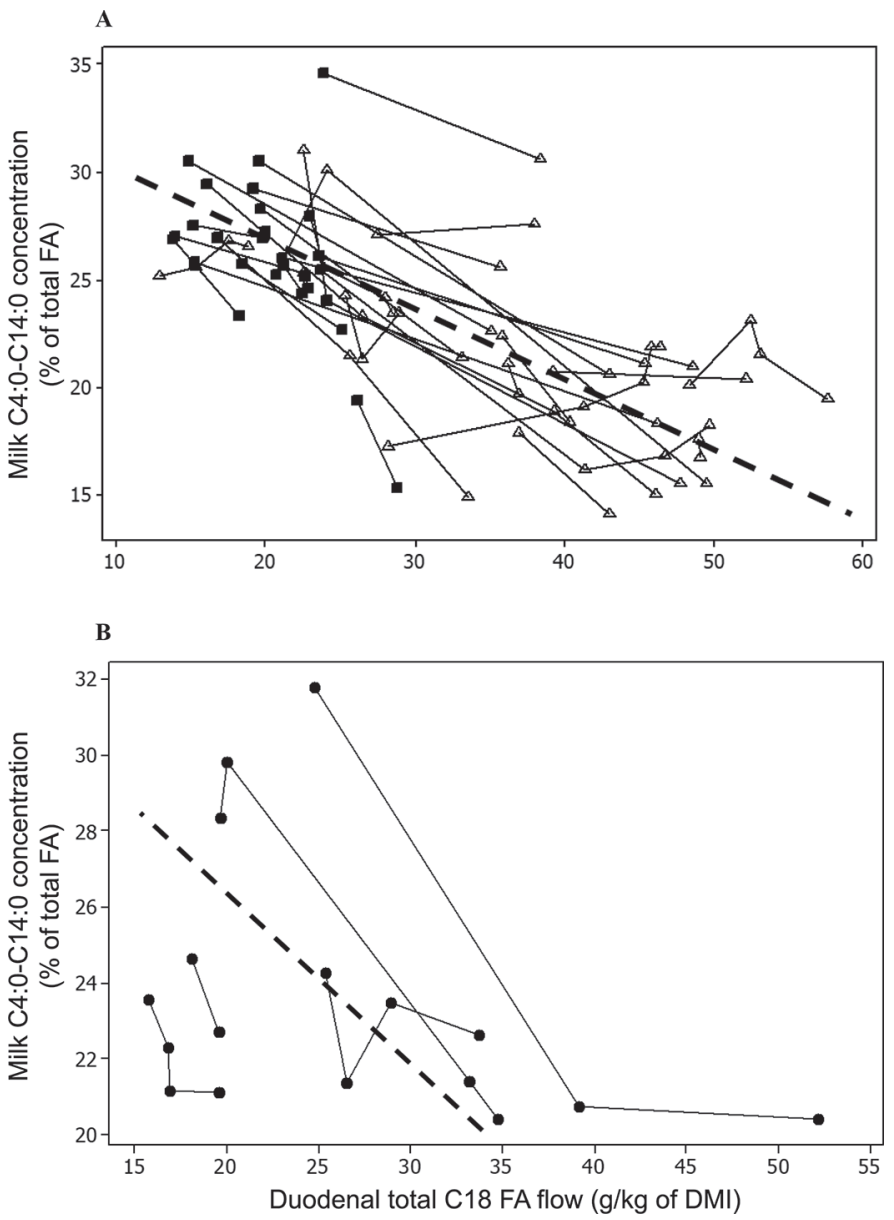

Figure 2. (A) Intra-experimental relationship between milk $\mathrm{C} 4$ 0-C14:0 concentration [Y, \% total fatty acids (FA)] and duodenal total C18 FA flow (X, g/kg of DMI), where $(\Delta)$ are the lipid diets and $(\mathbf{\square})$ are diets without lipid supplementation from the forage/concentrate/ lipids subset. The dashed line (- - ) shows the linear fitted model $[\mathrm{Y}$ $=33.3 \pm 1.10-0.32 \pm 0.03 \cdot \mathrm{X}$, number of experiments $\left(\mathrm{N}_{\exp }\right)=30$, number of treatments $\left(\mathrm{N}_{\text {trt }}\right)=80$, root mean square error (RMSE) $=2.29 \%$ of total FA, $\left.\mathrm{R}^{2}=0.74\right]$. (B) Intra-experimental relationship between milk C4:0-C14:0 concentration (Y, \% total FA) and duodenal total C18 FA flow (X, g/kg of DMI) from the fish subset. The dashed line $(--)$ shows the linear fitted model $(\mathrm{Y}=35.3 \pm 1.92-0.45 \pm$ $0.07 \cdot \mathrm{X}, \mathrm{N}_{\exp }=5, \mathrm{~N}_{\text {trt }}=17, \mathrm{RMSE}=1.79 \%$ of total $\left.\mathrm{FA}, \mathrm{R}^{2}=0.72\right)$.

ing duodenal C18 FA flow regardless which data set was considered.

For the different response models predicting milk trans C18:1 isomers, we obtained models with a $\mathrm{R}^{2}$ greater than 0.90, except for trans-4 and trans-10 C18:1, with the values of $\mathrm{R}^{2}$ varying from 0.57 to 0.86 (Table 1 ). We obtained quadratic models from their respective duodenal flows for trans- 4 and trans-16+cis-14 C18:1 when they were expressed in percentage of total FA, for trans $-6+7+8$, trans -9 , trans -12 , and trans- $13+14$ when they were expressed in grams per day and percentage of total FA, and for trans-11 C18:1 when the units grams per day were used (Figure 3A). The regression for milk 
trans-10 C18:1 yield presented a significant intercept $(3.86 \pm 1.20 \mathrm{~g} / \mathrm{d})$ and a slope equal to $0.27 \pm 0.05$ (Figure 3B). The linear regression of trans-10 C18:1 concentrations presented slopes of $0.84 \pm 0.14$ and 0.64 \pm 0.12 with the units of percentage of total FA and percentage of total C18 FA, respectively. Furthermore, linear regressions between milk yield of trans-15 and trans-16 + cis-14 C18:1 and their respective duodenal FA flow were obtained with a slope equal to $0.44 \pm$ 0.02 and $0.32 \pm 0.03$, and a root mean square error (RMSE) equal to 0.08 and $0.76 \mathrm{~g} / \mathrm{d}$, respectively.

For milk C18:2 isomers (except for cis-9,trans-11 CLA, which has double origin: rumen formation and provided from the desaturated trans-11 C18:1), we had
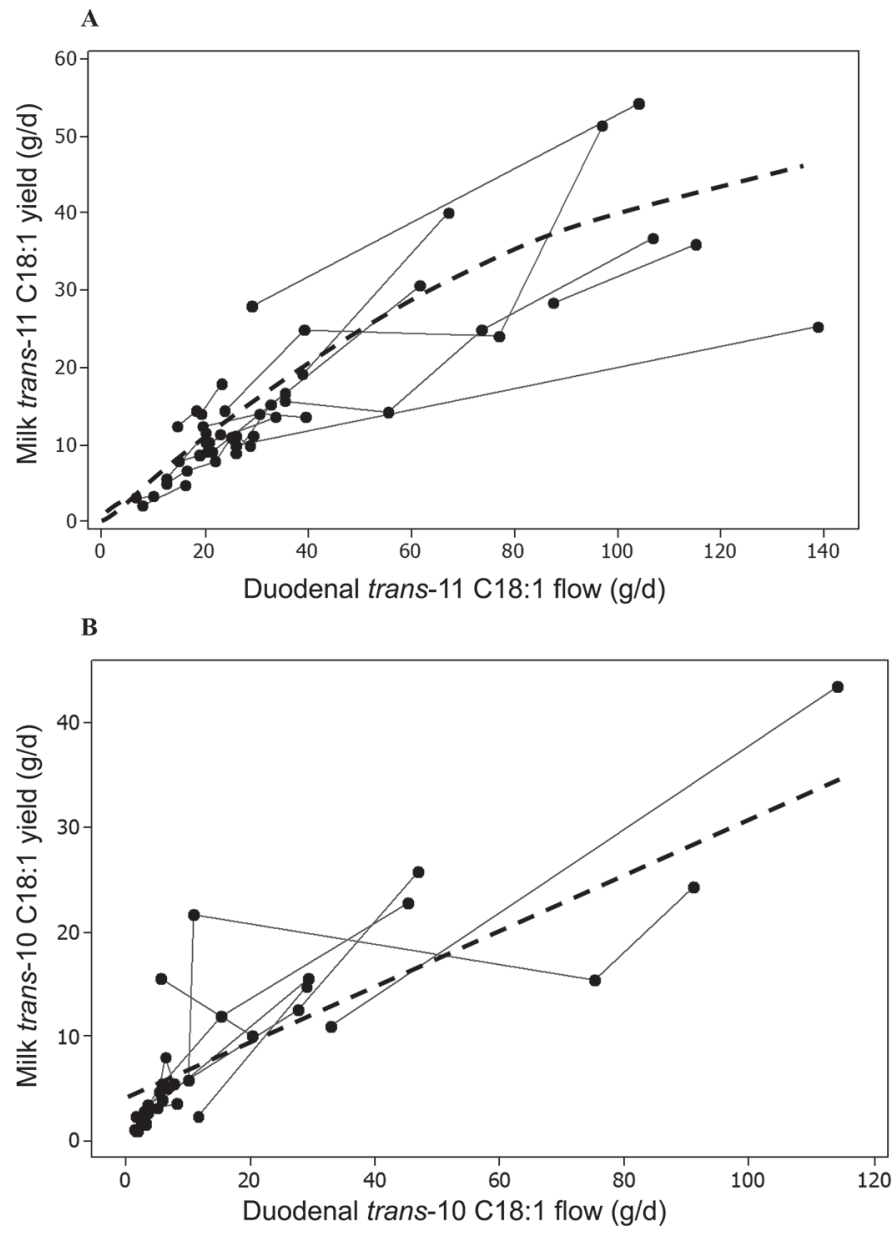

Figure 3. (A) Intra-experimental relationship between milk trans-11 C18:1 yield $(\mathrm{Y}, \mathrm{g} / \mathrm{d})$ and duodenal trans-11 C18:1 flow (X, $\mathrm{g} / \mathrm{d}$ ) from the forage/concentrate/lipids subset. The dashed line (- - ) shows the quadratic model $\left[\mathrm{Y}=0.55 \pm 0.04 \cdot \mathrm{X}-0.0019 \pm 0.0004 \cdot \mathrm{X}^{2}\right.$, number of experiments $\left(\mathrm{N}_{\exp }\right)=18$, number of treatments $\left(\mathrm{N}_{\text {trt }}\right)=49$, root mean square error (RMSE) $\left.=4.25 \mathrm{~g} / \mathrm{d}, \mathrm{R}^{2}=0.95\right]$. (B) Intraexperimental relationship between milk trans-10 C18:1 yield $(\mathrm{Y}, \mathrm{g} / \mathrm{d})$ and duodenal trans-10 C18:1 flow (X, g/d) from the forage/concentrate/lipids subset. The dashed line (- - ) shows the linear model (Y $=3.86 \pm 1.20+0.27 \pm 0.05 \cdot \mathrm{X}, \mathrm{N}_{\exp }=14, \mathrm{~N}_{\text {trt }}=37, \mathrm{RMSE}=5.11$ $\left.\mathrm{g} / \mathrm{d}, \mathrm{R}^{2}=0.70\right)$. linear regressions for C18:2n-6 (Table 2 and Figure 4), trans-10,cis-12 and trans-11,cis-13 CLA whatever the unit used, and trans-11,trans-13 CLA (when expressed in \% of total $\mathrm{C} 18 \mathrm{FA}$ ) and trans-11,cis-15 C18:2 (when expressed in \% of total FA and total C18 FA) according to their respective duodenal FA flow. The slopes for C18:2n-6, trans-10, cis-12, and trans-11, cis-13 CLA yield models were $0.24 \pm 0.08,0.41 \pm 0.06$, and $0.47 \pm$ 0.02 , respectively. The slopes of $\mathrm{C} 18: 2 \mathrm{n}-6$ concentration models varied between $0.45 \pm 0.18$ (when expressed in $\%$ of total FA) and $0.54 \pm 0.05$ (when expressed in $\%$ of total C18 FA), whereas that of trans-11,trans-13 CLA (\% of total C18 FA) was $0.69 \pm 0.03$ and those of trans-11,cis-13 CLA were $0.73 \pm 0.06$ (when expressed in $\mathrm{g} / \mathrm{d}$ ) and $0.44 \pm 0.03$ (when expressed in $\%$ of total FA), respectively. We obtained quadratic models for trans-11,trans-13 CLA yield or concentration (when expressed in \% of total FA) and trans-11,cis-15 and trans-9,cis-12 C18:2 whatever the units used (Table $2)$. Intercepts were all significant except for trans11,trans-13 CLA and trans-11,cis-15 C18:2 whatever the units used, trans-10, cis-12 CLA concentration when the model was expressed in \% of total C18 FA and trans-11,cis-13 CLA yield.

Concerning C18:3n-3, we obtained quadratic regressions (Table 2 and Figure 5), with $\mathrm{R}^{2}$ varying from 0.97 to 0.98 . The intercept was not significant for all models, whatever the units used.

Concerning the sums of substrates and products of mammary $\Delta^{9}$-desaturase activity, we obtained models with $\mathrm{R}^{2}$ greater than 0.84; RMSE were 6.16 and 33.9 $\mathrm{g} / \mathrm{d}, 0.46$ and $2.39 \%$ of total FA, and 0.82 and 3.06 (\% of total C18 FA) for the sum of cis-9,trans-11 C18:2 + trans-11 C18:1 and for the sum of C18:0 + cis-9 C18:1, respectively (Table 3 and Figure 6). Whatever the units used, the relationships were linear between milk yields or concentrations and duodenal flows, with significant intercepts except for the sum of trans-11 C18:1 and cis-9,trans-11 CLA expressed in percentage of total C18 FA. Adjusted models of the amount desaturated of $\mathrm{C} 18: 0$ into cis-9 $\mathrm{C} 18: 1$ and trans-11 C18:1 into cis-9,trans-11 CLA according to estimated mammary uptake are presented in Table 6. Estimated mammary uptake of $\mathrm{C} 18: 0$ and cis-9 $\mathrm{C} 18: 1$ was $256( \pm 11)$ and $23( \pm 2.3) \mathrm{g} / \mathrm{d}$ for their respective milk yields of 180 $( \pm 7.7)$ and $6.9( \pm 0.40) \mathrm{g} / \mathrm{d}$. The adjusted models had a significant intercept and $\mathrm{R}^{2}$ between 0.82 and 0.96 . The slopes indicated that approximately $25 \%($ slope $=0.23)$ of the trans-11 C18:1 uptake and half of the C18:0 uptake (slope $=0.55$ ) were desaturated into cis-9, trans-11 CLA and cis-9 C18:1, respectively. The calculated contribution of $\mathrm{C} 18: 0$ and trans-11 C18:1 desaturation to respective cis-9 C18:1 and cis-9,trans-11 CLA yields in milk fat was $83.8 \%( \pm 0.75)$ and $86.8 \%( \pm 2.8)$. 


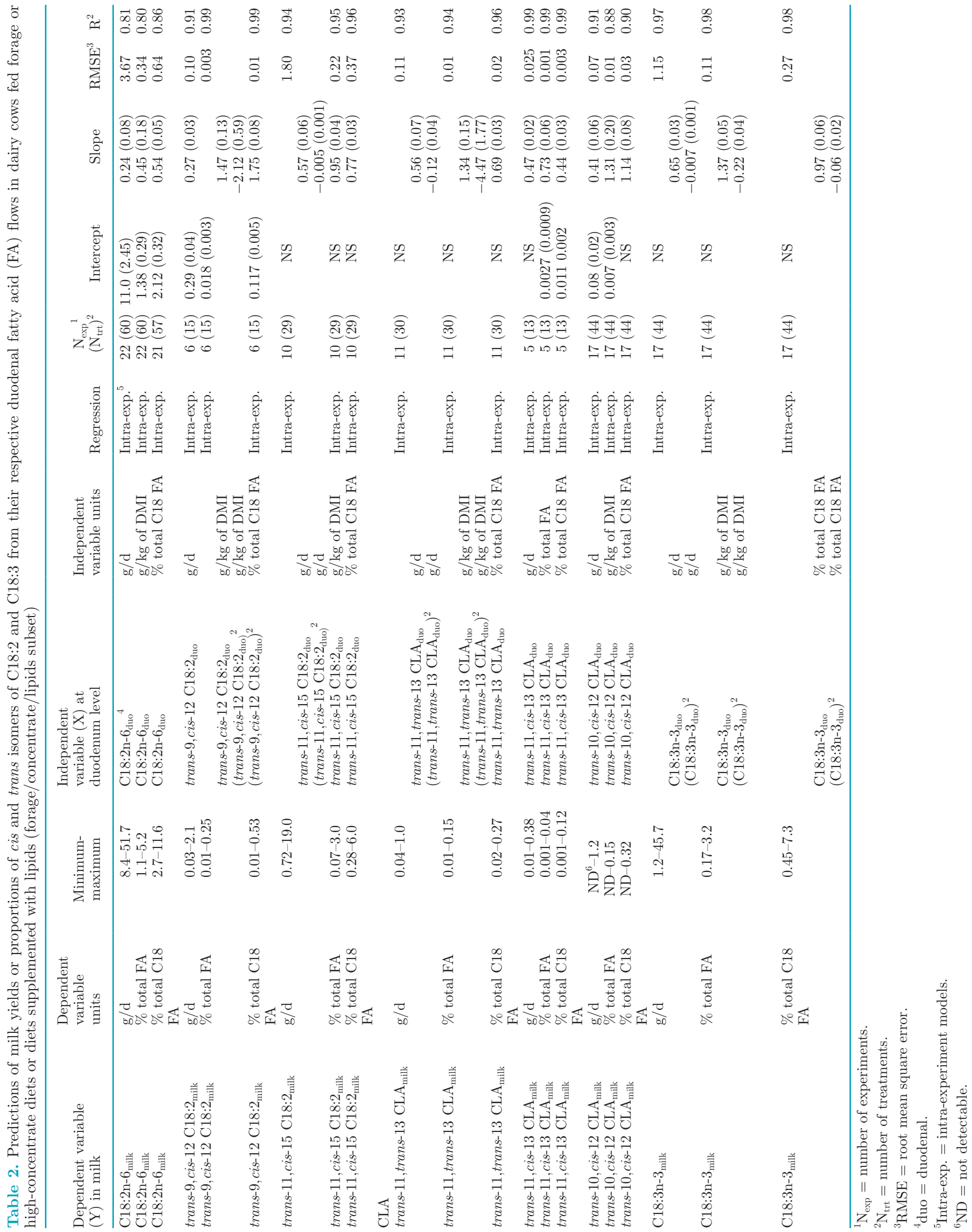




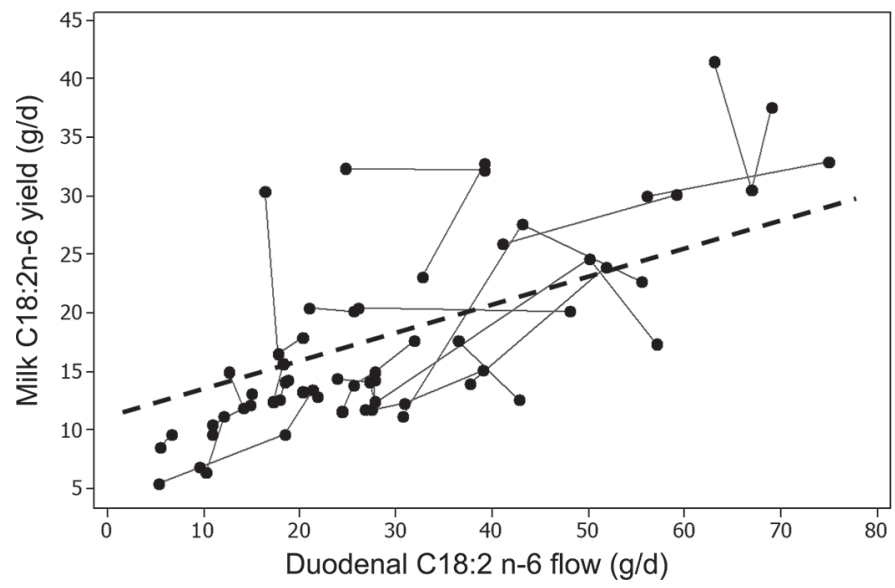

Figure 4. Intra-experimental relationship between milk C18:2n-6 yield (X, g/d) and duodenal C18:2n-6 flow (Y, g/d) from the forage/ concentrate/lipids subset. The dashed line (- - -) shows the linear model $(\mathrm{Y}=11.0 \pm 2.45+0.24 \pm 0.08 \cdot \mathrm{X}$, number of experiments $=$ 22 , number of treatments $=60$, root mean square error $=3.67 \mathrm{~g} / \mathrm{d}$, $\left.\mathrm{R}^{2}=0.81\right)$.

\section{Milk SFA, and Odd- and Branched-Chain Fatty Acids}

Concerning de novo synthesized FA, the milk C4:0-C14:0 yield was related positively to the sum of ruminal acetate and butyrate concentrations and negatively to the duodenal flow of total C18 FA with a positive intercept $(138 \pm 68.1 \mathrm{~g} / \mathrm{d})$. The respective contribution of the sum of ruminal acetate and butyrate and the duodenal flow of total C18 FA in the total variance of that model were 21 and $4 \%$. The intraexperiment models of milk C16:0 yield and concentration from duodenal C16:0 flow were quadratic, with $\mathrm{R}^{2}$ equal to 0.74 and 0.54 , respectively (Table 4). Similarly,

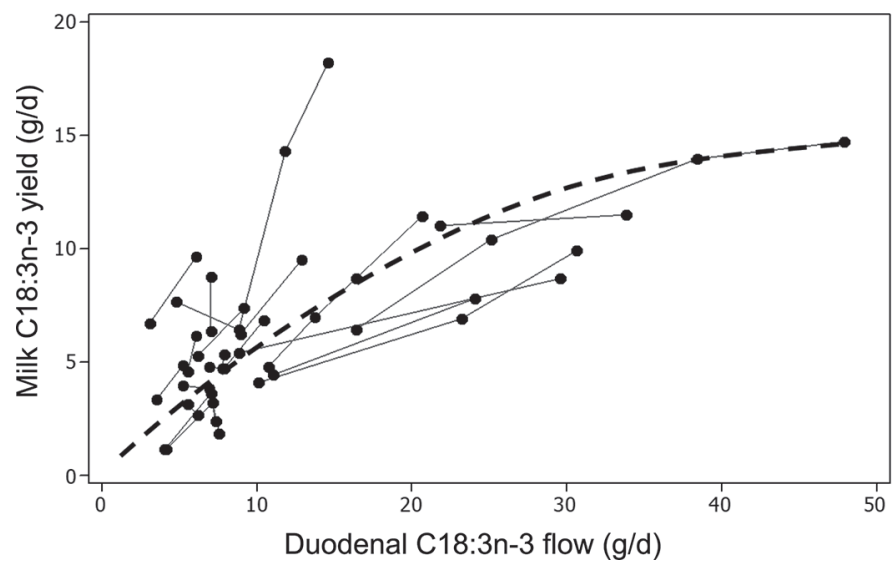

Figure 5. Intra-experimental relationship between milk C18:3n-3 yield $(\mathrm{Y}, \mathrm{g} / \mathrm{d}$ ) and duodenal C18:3n-3 flow (X, g/d) from the forage/ concentrate/lipids subset. The dashed line (- - ) shows the quadratic model $\left(\mathrm{Y}=0.65 \pm 0.03 \cdot \mathrm{X}-0.007 \pm 0.001 \cdot \mathrm{X}^{2}\right.$, number of experiments $=17$, number of treatments $=44$, root mean square error $=1.15 \mathrm{~g} / \mathrm{d}$, $\left.\mathrm{R}^{2}=0.97\right)$.

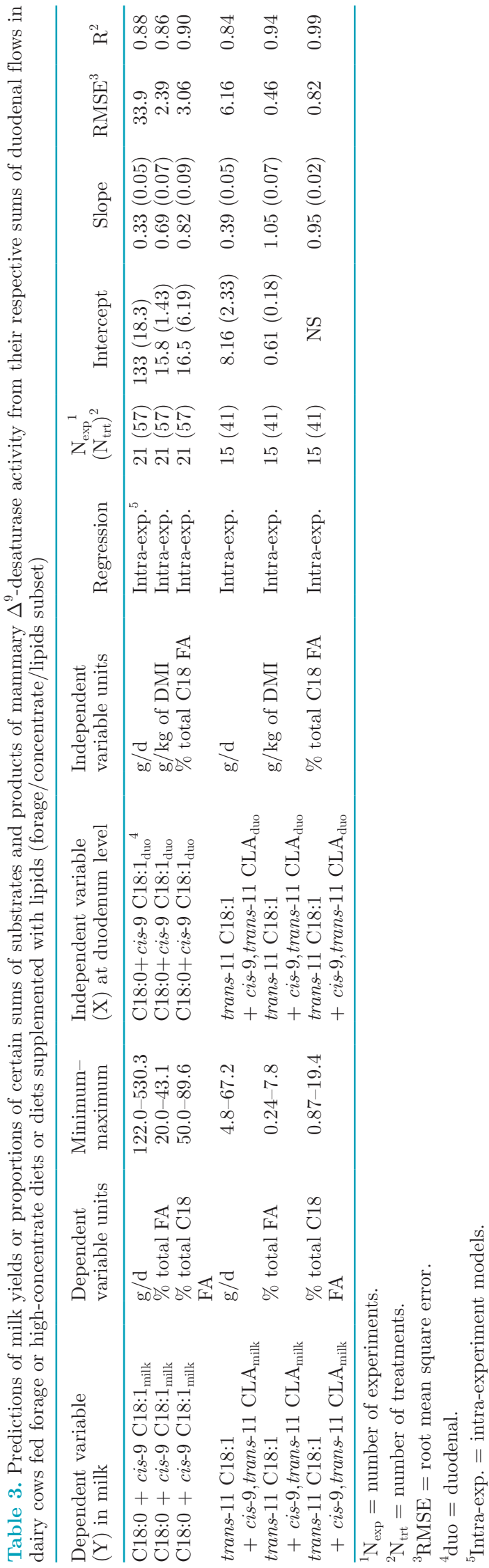

Journal of Dairy Science Vol. 102 No. 4, 2019 


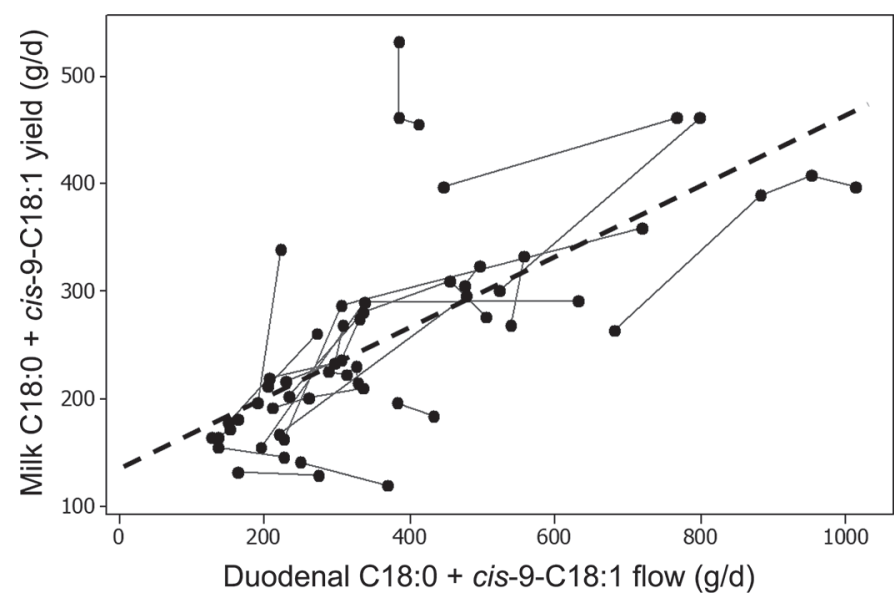

Figure 6. Intra-experimental relationship between the sum of milk C18:0 and cis-9 C18:1 yield (Y, g/d) and duodenal flow of the sum of $\mathrm{C} 18: 0$ and cis-9 C18:1 (X, g/d) from the forage/concentrate/lipids subset. The dashed line (- - ) shows the linear model ( $\mathrm{Y}=133 \pm 18.3$ $+0.33 \pm 0.05 \cdot \mathrm{X}$, number of experiments $=21$, number of treatments $=57$, root mean square error $\left.=33.9 \mathrm{~g} / \mathrm{d}, \mathrm{R}^{2}=0.88\right)$.

the intra-experiment models of milk C18:0 yield and concentration (\% of total FA) from duodenal C18:0 flow were quadratic with $\mathrm{R}^{2}$ varying between 0.89 and 0.99 , respectively (Table 4). The linear model of C18:0 concentration when expressed in total C18 FA presented a slope of $0.31 \pm 0.04$ and $a R^{2}$ of 0.83 .

The intra-experimental models of milk yields of $\mathrm{C} 15: 0$, iso-C17:0, and anteiso-C17:0 from their respective duodenal flows presented $\mathrm{R}^{2}$ between 0.82 and 0.98 (Table 4), whereas the predictions of the concentrations of all odd- and branched-chain fatty acids in milk from their concentrations in duodenal DM ( $\mathrm{g} / \mathrm{kg}$ of DMI) or concentrations in duodenal total FA had $\mathrm{R}^{2}$ between 0.74 and 0.97. Predictions of milk yield of C15:0 and C17:0 from dietary starch content (positive slope) or ruminal $\mathrm{pH}$ (negative slope) had slightly lower $\mathrm{R}^{2}$ than the models obtained with duodenal flows as predictors. Prediction of yields of iso-C15:0, anteiso-C15:0, and anteiso-C17:0 from dietary starch, ruminal acetate: propionate ratio, or ruminal acetate had $\mathrm{R}^{2}$ between 0.50 and 0.88 (Table 4 and Figures 7A and 7B).

\section{Milk FA with 18, 20, or 22 Atoms of Carbon}

For the fish subset, we obtained similar quadratic models of milk C18 FA yield from their duodenal flow (Table 5 and Figure 1B) than for the FCL subset. Moreover, the model predicting milk $\mathrm{C} 4: 0$ to $\mathrm{C} 14: 0$ yield from acetate+butyrate ruminal concentration and total duodenum C18 FA flow had similar coefficients than those in the FCL subset, but they were not significant, probably because of the low number of treatments available $\left(\mathrm{N}_{\mathrm{trt}}=13\right)$.
We calculated intra-experiment regressions for eicosapentaenoic acid (EPA; C20:5n-3), docosapentaenoic acid (DPA; C22:5n-3), and docosahexaenoic acid (DHA; C22:6n-3) expressed in grams per day or percentage of total FA from their duodenal flows with $\mathrm{R}^{2}$ varying from 0.23 to 0.83 (Table 5). Models of EPA yield and concentration were quadratic according to its duodenal flow with slopes equal to $0.05 \pm 0.01$ and $2.85 \pm 0.41$, respectively. When expressed in grams per day and percentage of total FA, milk DHA yield was linearly related to its respective duodenal FA flow, with slopes of $0.20 \pm 0.03$ and $0.59 \pm 0.09$, respectively. When expressed in grams per day and percentage of total of FA, the slopes of the linear milk DPA models were $0.24 \pm 0.11$ and $0.71 \pm 0.38$, respectively.

Whatever the units used, milk C18:3n-3 was linearly related to its duodenal flow with $\mathrm{R}^{2}$ values from 0.52 to 0.91 . The slopes were $0.26 \pm 0.04,0.39 \pm 0.07$, and 0.15 \pm 0.06 when expressed in grams per day, percentage of total FA, and percentage of total C18 FA, respectively. Global models of milk C18:2n-6 yield or concentration were positively dependent on its duodenal flow with $\mathrm{R}^{2}$ and slopes varying from 0.65 to 0.96 and $0.37 \pm$ 0.06 to $1.51 \pm 0.08$, respectively (Table 5 ). For C18:0 and isomers of $\mathrm{C} 18: 1$, the models presented $\mathrm{R}^{2}$ values greater than 0.85 , except for cis-9 $\mathrm{C} 18: 1\left(\mathrm{R}^{2}=0.42\right)$. The models of milk C18:0 yield $(\mathrm{g} / \mathrm{d})$ and concentration (\% of total C18 FA) were linear, but quadratic when expressed in percentage of total FA. Models for trans-10 C18:1 presented a linear effect of duodenal trans-10 C18:1 whatever the unit used, with slopes of $0.43 \pm 0.01,1.08 \pm 0.04$, and $0.80 \pm 0.02$ for the units grams per day, percentage of total $\mathrm{FA}$, and percentage of C18 FA, respectively. Milk yield of trans-11 C18:1 had a quadratic relationship with duodenal trans-11 C18:1 flow, whereas the models for concentration presented a linear effect of duodenal trans-11 C18:1 flow. The model for trans-10,cis-12 CLA yield was linear with a slope of $0.43 \pm 0.06$ and a $\mathrm{R}^{2}$ of 0.88 , whereas the model for trans-10,cis-12 CLA concentration was quadratic with a $\mathrm{R}^{2}$ of 0.98 .

Concerning the desaturated FA, models of the sum of $\mathrm{C} 18: 0+$ cis-9 C18 were linear when they were expressed in grams per day or percentage of total C18 FA and the model expressed in percentage of total FA was quadratic. All models for the sum of milk trans-11 C18:1 and cis-9,trans-11 CLA were a linear function of their duodenal flow, with high $\mathrm{R}^{2}$ varying from 0.96 to 0.98. Adjusted models of the amount of desaturated C18:0 into cis-9 C18:1 and trans-11 C18:1 desaturated into cis-9,trans-11 CLA according to estimated mammary uptake are presented in Table 6. Estimated mammary uptake of $\mathrm{C} 18: 0$ and cis-9 $\mathrm{C} 18: 1$ was 210 $( \pm 39.5)$ and $35( \pm 5.0) \mathrm{g} / \mathrm{d}$ for respective milk yields of 


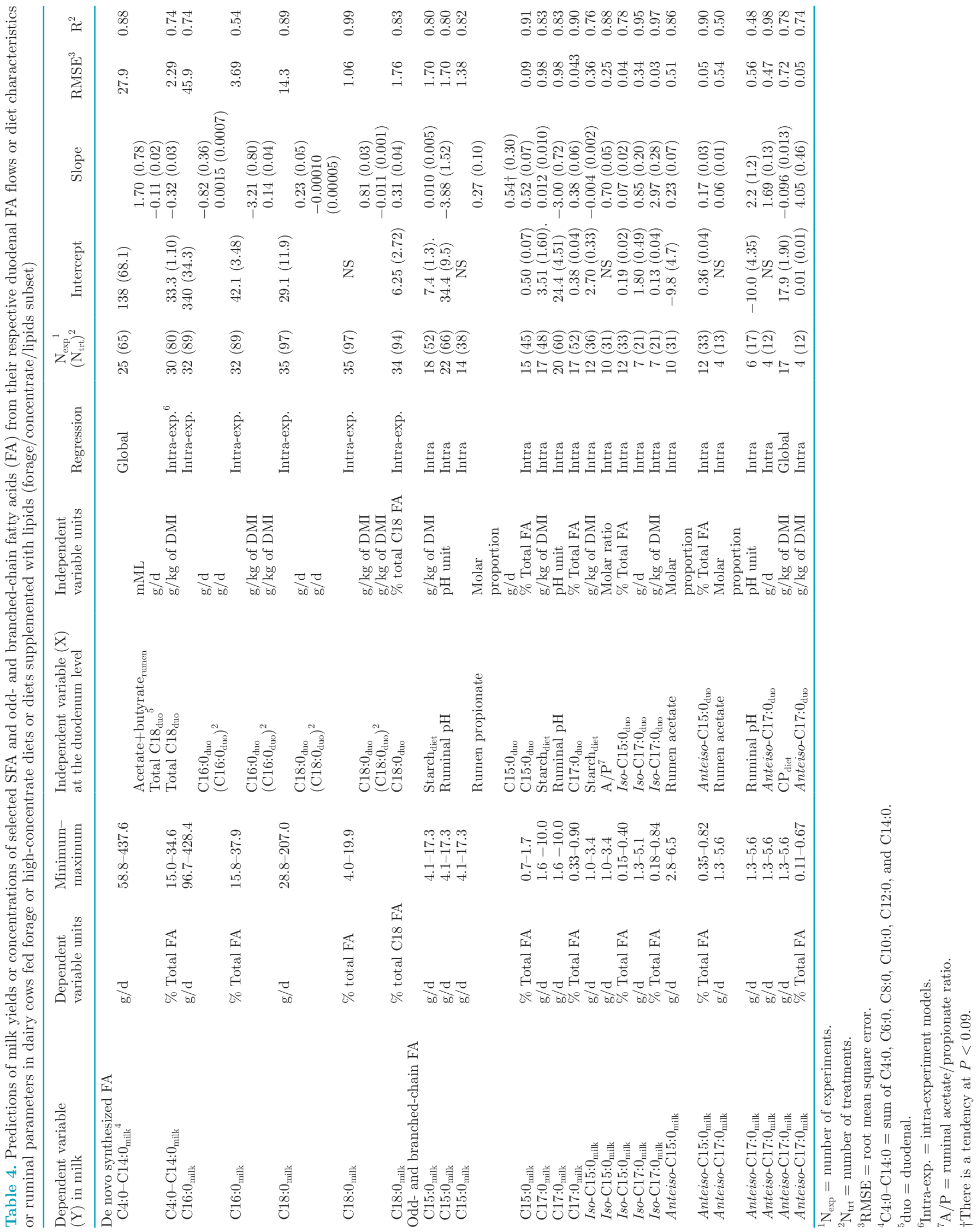


$142( \pm 25.7)$ and $9.9( \pm 1.23) \mathrm{g} / \mathrm{d}$. The adjusted models had no significant intercept and $\mathrm{R}^{2}$ was between 0.78 and 0.96 . The slopes indicated that approximately $25 \%$ (slope $=0.23$ ) of the trans-11 C18:1 uptake and half of the $\mathrm{C} 18: 0$ uptake (slope $=0.56$ ) were desaturated into cis-9,trans-11 CLA and cis-9 C18:1, respectively. The calculated contribution of C18:0 and trans-11 C18:1 desaturation to respective cis-9 $\mathrm{C} 18: 1$ and cis-9,trans-11 $\mathrm{C} 18: 2$ yields was $80.2 \%( \pm 0.75)$ and $73.0 \%( \pm 7.4)$.

\section{DISCUSSION}

\section{Milk Total C18 Fatty Acids, Cis and Trans Isomers of C18:1 and C18:2, and C18:3n-3}

General Considerations. We selected 3 units of expression to predict milk FA, in grams per day or a percentage of total FA for all milk FA, and percentage of total milk C18 FA for milk isomers of C18:1 and $\mathrm{C} 18: 2$, and C18:3n-3. In their review, Glasser et al. (2008b) stated that direct prediction of the yield of individual C18 FA on a gram per day basis could not be established from their duodenal flow because milk total C18 yield could not be precisely predicted from the corresponding duodenal flow. However, during diet formulation with linear programming to optimize a given constraint (e.g., optimize milk yield of C18:3n-3), the ratio as a percentage of total $\mathrm{FA}$ or a percentage of total $\mathrm{C} 18 \mathrm{FA}$ is not additive, which often prevents finding an optimal solution to the dietary constraints. Consequently, we decided to present equations that rely on flows from the duodenum to the mammary gland with grams per day as units. Moreover, these units are coherent with the prediction of laws or responses of milk from changes in duodenal flows as recently proposed in the renewal of feed unit system for ruminants (INRA, 2018). However, we also used a composition approach, with FA in milk being expressed as a percentage of total FA or as a percentage of C18 FA, for comparison with the review of Glasser et al. (2008b).

We decided to provide a set of equations including prediction of milk individual FA from their duodenal flows, from ruminal characteristics, or from dietary constituents. It must be stressed that this approach is more adapted to the prediction of the yields or the concentrations of individual FA or a group of FA (e.g., C4:0 to C14:0) rather than a complete profile of milk FA. Indeed, the milk FA profile is not the sum of FA independently synthesized or taken up, but rather results from interaction between the uptake of long-chain FA, de novo mammary lipogenesis, desaturation of FA, and esterification of glycerol molecule (Ferlay et al., 2017). These interactions have not been addressed directly here, with 2 exceptions. First, we provided a specific set of equations to predict milk FA profile for cows fed marine products, assuming that long-chain PUFA may affect the mammary lipogenesis (Angulo et al., 2012), mammary $\Delta^{9}$-desaturase activity (Kairenius et al., 2015) and possibly the transfer of preformed FA into the mammary gland (Vahmani et al., 2014). Second, the reduction of de novo mammary lipogenesis by duodenal total C18 FA flows or concentrations (Shingfield et al., 2010) has been partly taken into account by indexing the prediction of milk C4:0 to C14:0 on the availability of their ruminal precursors but also on the duodenal flow of total C18 FA (see below).

Total C18 Fatty Acids. With the FCL subset, the positive intra-experiment relationship between duodenal C18 FA flow and milk C18 FA yield was quadratic
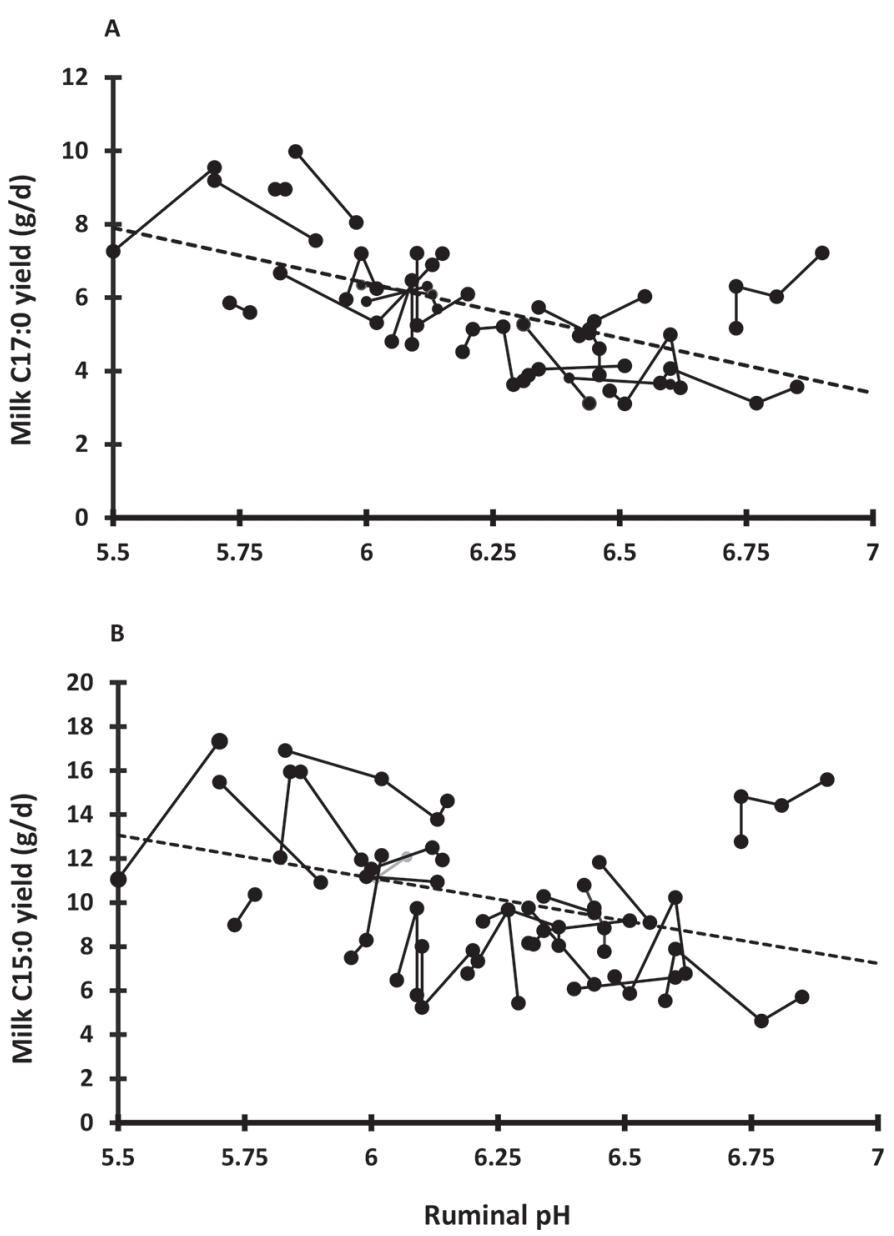

Figure 7. (A) Intra-experimental relationship between the milk C17:0 yield ( $\mathrm{Y}, \mathrm{g} / \mathrm{d}$ ) and the ruminal $\mathrm{pH}(\mathrm{X})$ from the forage/concentrate/lipids subset. The dashed line (- - ) shows the linear model [Y $=24.4( \pm 4.51)-3.00( \pm 0.72) \cdot \mathrm{X}$, number of experiments $\left(\mathrm{N}_{\exp }\right)=20$, number of treatments $\left(\mathrm{N}_{\text {trt }}\right)=60$, root mean square error (RMSE) $=$ $0.98, \mathrm{R}^{2}=0.83$. (B) Intra-experimental relationship between the milk $\mathrm{C} 15: 0$ yield $(\mathrm{Y}, \mathrm{g} / \mathrm{d})$ and the ruminal $\mathrm{pH}(\mathrm{X})$ from the forage/concentrate/lipids subset. The dashed line (- - ) shows the linear model [Y $=34.4( \pm 9.5)-3.88( \pm 1.53) \cdot \mathrm{X}, \mathrm{N}_{\mathrm{exp}}=22, \mathrm{~N}_{\mathrm{trt}}=66, \mathrm{RMSE}=1.70$, $\left.\mathrm{R}^{2}=0.80\right]$. 


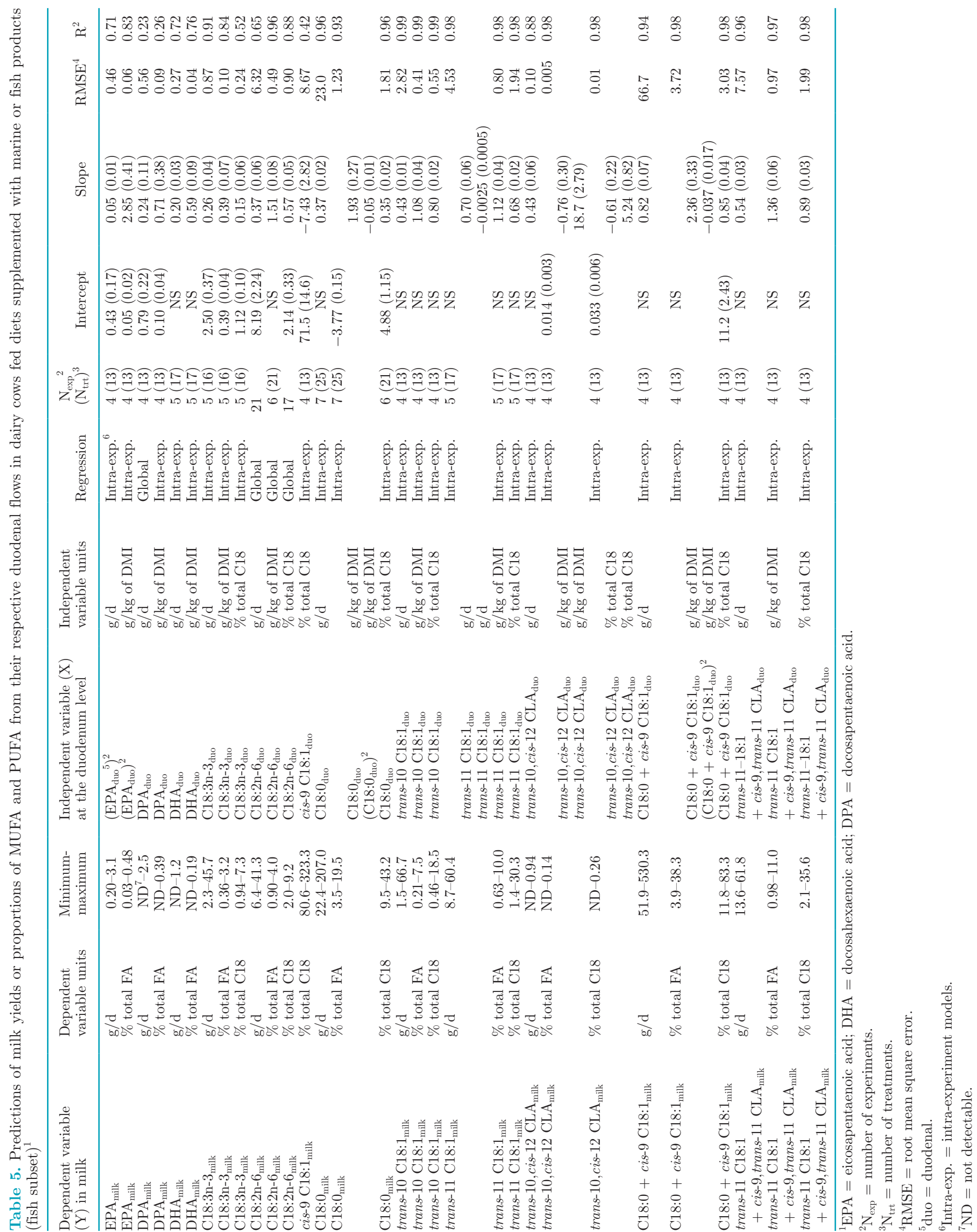




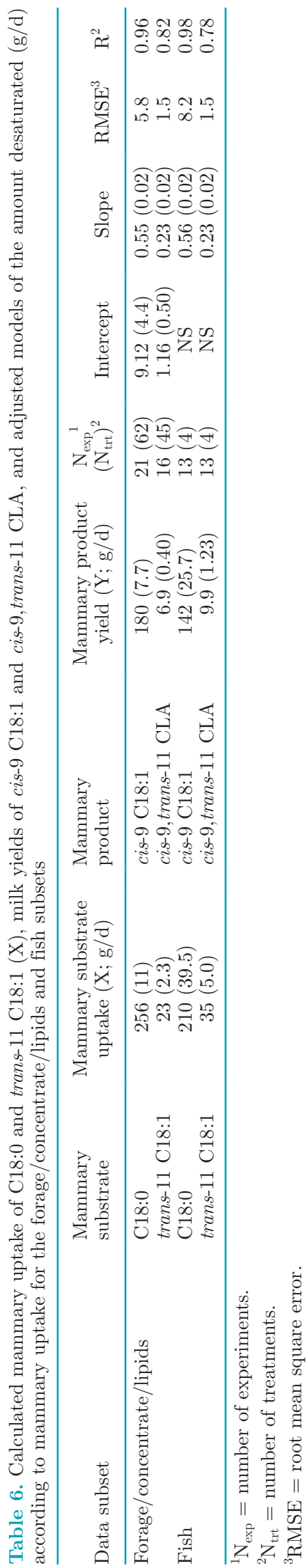

and was close to that reported by Glasser et al. (2008b). Our model presented a lower intercept and RMSE than those of Glasser et al. (2008b). The transfer efficiency of C18 FA was relatively high (linear coefficient of 0.66 ) and was higher than that (0.46) indicated by Glasser et al. (2008b). Moreover, the resulting milk C18 yield plateaued at a value of $470 \mathrm{~g} / \mathrm{d}$ for a duodenal C18 FA flow of $1,250 \mathrm{~g} / \mathrm{d}$ corresponding to an increase of C18 duodenal flow of $1,000 \mathrm{~g} / \mathrm{d}$ above the basal flow of control diets. A similar pattern of response of milk C18 FA secretion to duodenal flow of C18 FA was reported by Glasser et al. (2008b) with a similar maximal response $(450 \mathrm{~g} / \mathrm{d})$ but for a lower increase $(605 \mathrm{~g} / \mathrm{d})$ in C18 FA duodenal flow. These variations could be due to the different meta-designs between the 2 meta-analyses. In fact, among the selected publications from Glasser et al. (2008b), experiments on postruminal infusions of trans-10,cis-12 CLA were included and this FA could decrease the capacity of the mammary gland to take up C18 FA by altering the activity of LPL (Shingfield et al., 2009) and thus change the transfer efficiency of C18 FA. Concerning this relationship, milk yield of C18 FA varied more strongly for similar duodenal flows with lipid-supplemented diets (Figure 1A, black squares, $\mathrm{Y}$ $=247 \pm 39.7+0.20 \pm 0.05 \cdot \mathrm{X}, \mathrm{N}_{\text {trt }}=63, \mathrm{RMSE}=104$ $\mathrm{g} / \mathrm{d}, \mathrm{R}^{2}=0.21$ ) than with diets without lipids (black circles, $\mathrm{Y}=115 \pm 25.9+0.50 \pm 0.06 \cdot \mathrm{X}, \mathrm{N}_{\text {trt }}=33$, $\left.\mathrm{RMSE}=54.5 \mathrm{~g} / \mathrm{d}, \mathrm{R}^{2}=0.67\right)$. We can rely on the high variability of $\mathrm{C} 18 \mathrm{FA}$ yield with lipid-supplemented diets given that increasing duodenal flow of $\mathrm{C} 18 \mathrm{FA}$ induced a linear decrease in milk $\mathrm{C} 4: 0$ to $\mathrm{C} 14: 0$ concentration (Figures 2A and 2B) and a quadratic increase in milk C18 FA yield (Table 4 and Figure 1A). This illustrates the changes in milk FA concentrations associated with the reduction in milk fat yield when lipid-supplemented diets were fed to cows, which increased the total C18 FA flows at the duodenum (Prado et al., 2018) and the C18 FA availability for the mammary gland (Glasser et al., 2008b).

The decrease in milk $\mathrm{C} 4: 0-\mathrm{C} 14: 0$ yield in the case of supplementation of diets with UFA could be due to an inhibitory effect of several intermediates of ruminal biohydrogenation (as trans-10,cis-12 CLA, or trans-10 C18:1; Bauman and Griinari, 2003). We confirmed this hypothesis since milk trans-10 C18:1 yield and milk C4: $0-\mathrm{C} 14: 0$ yield were negatively correlated $(\mathrm{r}=-0.585$, $P<0.01$ ), as were milk trans-10 C18:1 and C4:0-C14: 0 concentrations (\% of total FA) for the FCL subset (r $=-0.669, P<0.01$, data not shown).

Another explanation relative to the decreased $\mathrm{C} 4$ : 0-C14:0 yield with high-lipid diets could be due to a decrease in DMI $(\mathrm{DMI}=18.1 \pm 4.8$ and $17.2 \pm 4.2$ $\mathrm{kg} / \mathrm{d}$ for control diets and diets supplemented with lipids (data not shown) in accordance with Faverdin 
et al. (2018) or competition of C18 FA in short-chain FA esterification, as already suggested by Glasser et al. (2008b). Thus, high C18 FA supply to the mammary gland could modify both C18 FA uptake and de novo FA synthesis (Figures 1A and 2B).

Composition of C18 Fatty Acids. The linear models (expressed as a percentage of total C18 FA) indicated that several FA concentrations in milk were closely related to their duodenal concentration, with slopes close to the bisector (cis-12, cis-13, and trans-12 C18:1, and trans-10,cis-12 CLA) suggesting similar C18 FA composition in the duodenum and milk. This could be due to the fact that the mammary gland takes up C18 FA preferentially from plasma triglycerides circulating in chylomicra or very low-density lipoproteins and nonesterified FA, instead of plasma cholesterol esters and phospholipids (Bernard et al., 2008).

Several observations can be made: the transfer efficiency $(<0.60)$ was low for cis-11, trans-4 and trans-5 C18:1; intermediate for trans-9, trans-10, trans-11, and trans-13+14 C18:1; and high (>0.80) for trans-15 and trans-16+cis-14 C18:1. Isomers of C18:1 with milk concentrations in the same range as trans- 4 and trans-5, trans- 10 and trans-11, and trans- 15 and trans16+cis-14 C18:1 had the same transfer efficiency, with lower uptake for minor FA and greater uptake by the mammary gland for FA of higher concentration (except for cis-11). The C18:2n-6 and C18:3n-3 are essential FA and had a different pattern (low transfer for C18: 2n-6 and C18:3n-3, but with a quadratic relationship for C18:3n-3). This could reflect different plasma availability of these FA for mammary uptake. Indeed, during intravenous infusion of triglycerides emulsions enriched in $\mathrm{C} 18: 3 \mathrm{n}-3$ or $\mathrm{C} 18: 2 \mathrm{n}-6$, the content of $\mathrm{C} 18$ : $3 \mathrm{n}-3$ in plasma phospholipids was increased but not for that of $\mathrm{C} 18: 2 \mathrm{n}-6$, indicating re-esterification in the liver for C18:3n-3, but not for C18:2n-6 (Stamey Lanier et al., 2013). Plasma phospholipids were less taken up by the mammary gland than triglycerides and nonesterified FA. This phenomenon could explain the limited transfer of $\mathrm{C} 18: 3 \mathrm{n}-3$ into milk fat because $\mathrm{C} 18: 3 \mathrm{n}-3$ is present highly in phospholipids (Bernard et al., 2008; Stamey Lanier et al., 2013). Moreover, a possible regulation of the glycerol transferase enzymes involved in the triglyceride synthesis (glycerol-3-phosphate acyltransferase, acylglycerol phosphate acyltransferase, and diacylglycerol O-acyltransferase) by $\mathrm{C} 18: 2 \mathrm{n}-6$ or $\mathrm{C} 18$ : 3n-3 availability could be implicated and interact with the transfer of these FA into milk (Bernard et al., 2008, 2018).

Finally, it cannot be ruled out that quadratic responses of milk C18:3n-3 to changes in duodenal C18: 3n-3 flows may be related to the statistical distribution of duodenal C18:3n-3 concentration; the difference between the 1st and 2nd quartiles of the C18:3n-3 distribution was $1.8 \mathrm{~g}$ of $\mathrm{C} 18: 3 \mathrm{n}-3 / \mathrm{kg}$ of DMI, whereas that between the $3 \mathrm{rd}$ and 4 th quartiles was $33.1 \mathrm{~g} / \mathrm{kg}$ of DMI, reflecting a skewed distribution toward the lowest values of duodenal C18:3n-3.

The quadratic models of total C18 FA, cis-15, trans $-6+7+8$, trans- 9 , trans- 11 , trans -12 , trans $-13+14$ C18:1, trans-11,cis-15 C18:2, and trans-11,trans-13 CLA yields suggest a limiting capacity of mammary gland to uptake these FA and thus a saturation of the LPL activity. It is possible to advance similar explanations for these FA than for C18:3n-3, without specific studies allowing consolidation of these aspects.

When models from the FCL subset were compared with those from fish subset, some models presented similar slopes (C18:2n-6, C18:0, and trans-11 C18:1 when expressed in percentage of total C18 FA), whereas differences in C18:3n-3 models were observed (quadratic vs. linear between the FCL and fish subsets).

In our study, the apparent transfer efficiency of EPA from the duodenum to milk increased quadratically when its duodenal flow increased. This is in contrast to the data of Loor et al. (2005) and Dallaire et al. (2014), who reported an apparent transfer efficiency between 14 and 18\%, respectively, during EPA infusion. Conversely, apparent DHA transfer efficiency was $20 \%$ in our meta-analysis, which is in the range of values (13 to 26\%) reported by Loor et al. (2005) and Dallaire et al. (2014). Differences between these results may be related to the difference between the quantities of long-chain FA available at the duodenum in our metaanalysis (between 0.1 and $7 \mathrm{~g} / \mathrm{d}$ for EPA and 0.2 and 6 $\mathrm{g} / \mathrm{d}$ for DHA) in comparison with doses infused in the duodenum (between 12 and $50 \mathrm{~g} / \mathrm{d}$ for EPA and DHA), and reflected by very different milk yields for EPA $(0$ to $4 \mathrm{~g} / \mathrm{d}$ for DHA in our meta-analysis vs. 10 to $20 \mathrm{~g} / \mathrm{d}$ with duodenal infusion) and DHA (0.1 to $1.3 \mathrm{~g} / \mathrm{d}$ in our meta-analysis vs. 3.2 to $10 \mathrm{~g} / \mathrm{d}$ with duodenal infusion). These results indicated that high doses of infused long-chain FA could alter the capacity of the mammary gland to regulate the uptake of these FA and thus they may not be appropriate for estimating the real transfer of these FA into milk.

Some models of our FCL subset are in agreement with previous predictive equations reported by Glasser et al. (2008b). Notably, the intercept and slope of the models of trans-9 and trans-10 C18:1 were similar to those of Glasser et al. (2008b), respectively, affirming that our models were robust.

\section{Desaturated Fatty Acids}

The models of the sum of desaturation substrates and products (expressed as a percentage of $\mathrm{C} 18 \mathrm{FA}$ ) 
presented slopes close to unity (Table 3), suggesting that from a composition approach, milk concentrations of desaturated FA and their saturated precursors were directly proportional to their profile in the duodenum. This allowed us to estimate the mammary uptake of these FA and the quantity of FA further desaturated. Our results clearly indicated that the amounts of desaturated FA were directly and linearly proportional to their precursor uptake, suggesting that mammary $\Delta^{9}$-desaturase activity was high and not limiting within the range of substrates taken up (47 to $486 \mathrm{~g} / \mathrm{d}$ and 14 to $148 \mathrm{~g} / \mathrm{d}$ for C18:0 and trans-11 C18:1, respectively, in the FCL subset, Supplemental Table S1; https://doi .org/10.3168/jds.2018-15194). In our analysis, the contribution of mammary desaturase activity to milk cis-9 C18:1 yield was $83.8 \%$, which is in line with the findings of Glasser et al. (2008b). However, this is higher than the proportion of oleic acid being synthesized endogenously, which is between 48 and $57 \%$ of the amount secreted in milk, as estimated in vivo in ewes using 13C-labeled stearic acid (Toral et al., 2017). Differences between species and feeding conditions may account for these variations. For cis-9,trans-11 CLA yields, our estimate of the mammary desaturase contribution $(87 \%)$ is slightly lower than that (95\%) obtained by Glasser et al. (2008b), possibly because duodenal infusions of this FA were included in their database. Using tracer methodology in vivo, high variations have been observed in the contribution of endogenous synthesis to milk cis-9,trans-11 CLA in cows and in goats (Bernard et al., 2010; Ferlay et al., 2017).

The relationships between the sums of C18:0 and cis9 C18:1 and trans-11 C18:1 and cis-9,trans-11 CLA on a daily basis $(\mathrm{g} / \mathrm{d})$ were different between the 2 subsets, but similar when expressed in percentage of C18 FA. This suggests that the activity of $\Delta^{9}$-desaturase was not affected by feeding fish oils, as indicated by the very similar slopes of C18:0 and trans-11 C18:1 uptake and their desaturation products, in line with data obtained in vivo (Ahnadi et al., 2002; Toral et al., 2012). In our database, the average C18:0 mammary uptake was $256 \mathrm{~g} / \mathrm{d}$ in the FCL subset associated with average duodenal flows of C18:0 of $240 \mathrm{~g} / \mathrm{d}$, whereas it was 210 and $250 \mathrm{~g} / \mathrm{d}$, respectively, in the fish subset. The mammary uptake and duodenal flow of trans-11 C18:1 were 23 and $28 \mathrm{~g} / \mathrm{d}$ in the FCL subset and 35 and 62 $\mathrm{g} / \mathrm{d}$ in the fish subset, respectively. These data taken together may indicate a lower mammary uptake of C18:0 and trans-11 C18:1 in proportion to their respective duodenal flows when cows are fed fish oil, with no associated change in mammary $\Delta^{9}$-desaturase activity in our conditions. This suggestion is in agreement with Bernard et al. (2017), who reported no modification in mRNA abundance of the SCD gene in cows fed diets with fish oil, but in disagreement with Ahnadi et al. (2002), Harvatine and Bauman (2006), and Angulo et al. (2012), who reported a decreasing effect of diets supplemented with marine products on gene expression of SCD.

\section{Odd- and Branched-Chain Fatty Acids}

Yields or concentrations of linear odd-chain FA C15:0 and C17:0 in milk fat were related to their duodenal flows or concentrations in duodenal FA, respectively. This indicates that milk secretion of these FA was partly from ruminal origin, since these FA are synthetized by ruminal organisms (Vlaeminck et al., 2005). However, the slopes of the models that represent apparent transfer efficiency from duodenal into milk were around 0.5 (when expressed on a yield basis for C15:0 and C17:0). This value is slightly lower than those reported by Vlaeminck et al. (2015) that estimated the contribution of duodenal odd-chain FA to milk yield to be between 0.63 and 0.67 . This indicates that part of the yield of these FA in milk arises from de novo mammary synthesis in line as reflected by the significant intercept of the model of milk C17:0 concentration (\% of total FA) and the significant contribution of ruminal propionate to the secretion of C15:0 (Table 4). This suggests that de novo synthesis of linear odd-chain FA contributes to a large extent to the secretion in milk of these FA, with propionyl-CoA arising from ruminal propionate, as a primer for lipogenesis in the mammary gland as previously reported in dairy goats by Massart-Leen et al. (1983). However, some differences exist between these 2 FA when the slopes of the models to predict their concentration in milk fat were considered (0.52 for C15:0 vs. 0.38 for C17:0, respectively), indicating that a greater proportion of C15:0 than of C17:0 was apparently transferred into milk fat, possibly due to the fact that part of C17:0 transferred into milk was desaturated into cis-9-C17:1 (Fievez et al., 2003).

Milk yields or concentrations of branched-chain FA were also related to their duodenal flows or concentrations. For iso-C17:0, apparent transfer between duodenum and milk (on a $\mathrm{g} / \mathrm{d}$ basis) was high ( associated with a high intercept $(1.80 \mathrm{~g} / \mathrm{d})$, whereas for anteiso-C17:0, the slope was greater than 1 . This reflects that milk yield of these FA exceeds their duodenal flow, as previously reported by Vlaeminck et al. (2006, 2015), which may be attributed to either mobilization from adipose tissue or to synthesis of the $2 \mathrm{FA}$ in the mammary gland. Mobilization of iso-C17:0 and anteiso-C17:0 from adipose tissue is probably of minor importance, because most of the trials included in that meta-analysis were designed with cows in mid-lactation when lipomobilization is negligible. In the mammary 
gland, the activity of FA synthase to elongate isovaleryl-CoA, 2-methylbutyryl-CoA, and isobutyryl-CoA to iso odd-chain and anteiso odd-chain FA seems to be negligible (Fievez et al., 2012; Vlaeminck et al., 2015). Conversely, we found a positive relationship between milk anteiso-C15:0 and anteiso-C17:0 yield and molar acetate proportion, which indicates that part of the yield of these FA arises from incorporation of $2 \mathrm{C}$ units on anteiso-C13:0 and anteiso-C15:0, respectively. In agreement with the fact that milk iso-C15:0 can positively predict ruminal acetate (Fievez et al., 2012), we also find that iso-C15:0 was positively related to acetate:propionate ratio, suggesting a similar incorporation of $2 \mathrm{C}$ units on iso-C13:0.

Milk concentration of anteiso-C17:0 was also negatively correlated with dietary CP content $(\mathrm{r}=-0.892$, $P<0.001$, for the FCL subset, data not shown), in agreement with Cabrita et al. (2003), who reported negative correlations between dietary $\mathrm{CP}$ content and milk concentrations of anteiso-C17:0 for diets based on corn silage with different types of rumen-degradable proteins. Concerning the negative relationship between C15:0, C17:0, and anteiso-C17:0 in milk and ruminal $\mathrm{pH}$ (and positive relationship with the starch content of diet), it could be explained by the increase in the concentration of milk C15:0 and C17:0 occurring when the animals were fed acidotic diets associated with a strong decrease in ruminal pH (Colman et al., 2010; Fievez et al., 2012).

In further development, we will aggregate the present models with the previously developed models of duodenal FA flows from FA intake; this will predict milk responses of FA to different dietary strategies based on underlying nutrient flows, in accordance with the renewal of feed unit system for ruminants. This step would have to consider interaction between different processes in the mammary gland to provide a whole predicted profile of milk FA in response to dietary characteristics.

\section{CONCLUSIONS}

The available meta-design analyzed contained numerous data, with several experimental factors studied [forage nature, percentage of concentrate, supplementation of diets with vegetable oils and seeds, and marine products (fish oils and algae)] in dairy cows. This meta-analysis indicates that the mainly predictive response models of $c i s$ and trans isomers of C18:1 and $\mathrm{C} 18: 2$, and $\mathrm{C} 18: 3 \mathrm{n}-3$ yields and concentrations had a $\mathrm{R}^{2}$ above 0.90 and a low RMSE. Our original results concern the predictive response models of milk odd- and branched-chain fatty acids, C18:1 and C18:2 isomers, and mammary de novo synthesized FA yields or concentrations according to their duodenal flow, and rumen digestive parameters or dietary characteristics. Predictive response models of EPA, DPA, and DHA were also obtained in the subset studying the effects of marine products. Several equations were established with very similar intercepts and slopes between the 2 subsets.

\section{ACKNOWLEDGMENTS}

The authors are grateful to C. Gérard (Néovia, Vannes, France) and B. Delord (Limagrain Europe, Gerzat, France), who funded this meta-analysis study through the Neovia (Vannes, France) and Limagrain (Gerzat, France) brands, respectively, which are greatly acknowledged for their financial support to the Lucas de Ofeu Aguiar Prado Convention Industrielle de Formation par la Recherche (CIFRE) scholarship (INRA, UMR Herbivores).

\section{REFERENCES}

Ahnadi, C. E., N. Beswick, L. Delbecchi, J. J. Kennelly, and P. Lacasse. 2002. Addition of fish oil to diets for dairy cows. II. Effects on milk fat and gene expression of mammary lipogenic enzymes. J. Dairy Res. 69:521-531.

Angulo, J., L. Mahecha, K. Nuernberg, G. Nuernberg, D. Dannenberger, M. Olivera, M. Boutinaud, C. Leroux, E. Albrecht, and L. Bernard. 2012. Effects of polyunsaturated fatty acids from plant oils and algae on milk fat yield and composition are associated with mammary lipogenic and SREBF1 gene expression. Animal 6:1961-1972.

ANSES (Agence Nationale de Sécurité sanitaire alimentation, Environnement, travail). 2011. Actualisation des apports nutritionnels conseillés pour les acides gras. Accessed Jan. 28, 2019. https:/ /www.anses.fr/sites/default/files/documents/NUT2006sa0359Ra .pdf.

Bauman, D. E., and J. M. Griinari. 2003. Nutritional regulation of milk fat synthesis. Annu. Rev. Nutr. 23:203-227.

Bernard, L., M. Bonnet, C. Delavaud, M. Delosière, A. Ferlay, H. Fougere, and B. Graulet. 2018. Milk fat globule in ruminant: Major and minor compounds, nutritional regulation and differences among species. Eur. J. Lipid Sci. Technol. 120:5-31.

Bernard, L., C. Leroux, and Y. Chilliard. 2008. Expression and nutritional regulation of lipogenic genes in the ruminant lactating mammary gland. Bioactive components of milk. Adv. Exp. Med. Biol. 606:67-108.

Bernard, L., J. Mouriot, J. Rouel, F. Glasser, P. Capitan, E. PujosGuillot, J. M. Chardigny, and Y. Chilliard. 2010. Effects of fish oil and starch added to a diet containing sunflower-seed oil on dairy goat performance, milk fatty acid composition and in vivo $\Delta^{9}$-desaturation of $[13 \mathrm{C}]$ vaccenic acid. Br. J. Nutr. 104:346-354.

Bernard, L., P. G. Toral, and Y. Chilliard. 2017. Comparison of mammary lipid metabolism in dairy cows and goats fed diets supplemented with starch, plant oil, or fish oil. J. Dairy Sci. 100:93389351.

Cabrita, A. R. J., A. J. M. Fonseca, R. J. Dewhurst, and E. Gomes, 2003. Nitrogen supplementation of corn silages. 2. Assessing rumen function using fatty acid profiles of bovine milk. J. Dairy Sci. 86:4020-4032.

Chapoutot, P., O. Martin, P. Nozière, and D. Sauvant. 2015. Systool Web, a new one-line application for the French INRA « systali » project. Page 265 in the 66th Annual Meeting of the European Society of Animal Science. Wageningen Academic Publishers, Warsaw, Poland. 
Chelikani, P. K., J. A. Bell, and J. J. Kennelly. 2004. Effect of feeding or abomasal infusion of canola oil in Holstein cows 1. Nutrient digestion and milk composition. J. Dairy Res. 71:279-287.

Chilliard, Y., F. Glasser, A. Ferlay, L. Bernard, J. Rouel, and M. Doreau. 2007. Diet, rumen biohydrogenation and nutritional quality of cow and goat milk fat. Eur. J. Lipid Sci. Technol. 109:828855.

Colman, E., W. B. Fokkink, M. Craninx, J. R. Newbold, B. De Baets, and V. Fievez. 2010. Effect of induction of subacute ruminal acidosis on milk fat profile and rumen parameters. J. Dairy Sci. 93:4759-4773.

Dallaire, M. P., H. Taga, L. Ma, B. A. Corl, R. Gervais, Y. Lebeuf, F. J. Richard, and P. Y. Chouinard. 2014. Effects of abomasal infusion of conjugated linoleic acids, Sterculia foetida oil, and fish oil on production performance and the extent of fatty acid $\Delta^{9}$ desaturation in dairy cows. J. Dairy Sci. 97:6411-6425.

Elgersma, A. 2015. Grazing increases the unsaturated fatty acid concentration of milk from grass-fed cows: A review of the contributing factors, challenges and future perspectives. Eur. J. Lipid Sci. Technol. 117:1345-1369.

Faverdin, P., D. Sauvant, L. Delaby, S. Lemosquet, J. B. Daniel, and P. Schmidely. 2018. Dry matter intake and milk yield responses to dietary changes. Pages 149-176 in INRA Feeding System for Ruminants. P. Nozière D. Sauvant, and L. Delaby, ed. Wageningen Academic Publishers, Wageningen, the Netherlands.

Ferlay, A., L. Bernard, A. Meynadier, and C. Malpuech-Brugère. 2017. Production of trans and conjugated fatty acids in dairy ruminants and their putative effects on human health: A review. Biochimie 141:107-120.

Ferlay, A., M. Doreau, C. Martin, and Y. Chilliard. 2013. Effects of incremental amounts of extruded linseed on the milk fatty acid composition of dairy cows receiving hay or corn silage. J. Dairy Sci. 96:6577-6595.

Fievez, V., E. Colman, J. M. Castro-Montoya, I. Stefanov, and B. Vlaeminck. 2012. Milk odd- and branched-chain fatty acids as biomarkers of rumen function - An update. Anim. Feed Sci. Technol. 172:51-65

Fievez, V., B. Vlaeminck, M. S. Dhanoa, and R. J. Dewhurst. 2003 Use of principal component analysis to investigate the origin of heptadecenoic and conjugated linoleic acids in milk. J. Dairy Sci. 86:4047-4053.

Glasser, F., A. Ferlay, and Y. Chilliard. 2008a. Oilseed lipid supplements and fatty acid composition of cow milk: A meta-analysis. J. Dairy Sci. 91:4687-4703.

Glasser, F., A. Ferlay, M. Doreau, P. Schmidely, D. Sauvant, and Y. Chilliard. 2008b. Long-chain fatty acid metabolism in dairy cows: A meta-analysis of milk fatty acid yield in relation to duodenal flows and de novo synthesis. J. Dairy Sci. 91:2771-2785.

Glasser, F., P. Schmidely, D. Sauvant, and M. Doreau. 2008c. Digestion of fatty acids in ruminants: A meta-analysis of flows and variation factors: 2. C18 fatty acids. Animal 2:691-704

Harvatine, K. J., and D. E. Bauman. 2006. SREBP1 and thyroid hormone responsive spot 14 (S14) are involved in the regulation of bovine mammary lipid synthesis during diet-induced milk fat depression and treatment with CLA. J. Nutr. 136:2468-2474.

INRA. 2018. INRA feeding system for ruminant. Wageningen Academic Publishers, Wageningen, the Netherlands.

Kairenius, P., A. Ärölä, H. Leskinen, V. Toivonen, S. Ahvenjärvi, A. Vanhatalo, P. Huhtanen, T. Hurme, J. M. Griinari, and K. J. Shingfield. 2015. Dietary fish oil supplements depress milk fat yield and alter milk fatty acid composition in lactating cows fed grass silage-based diets. J. Dairy Sci. 98:5653-5671. https://doi.org/10 .3168/jds.2015-9548.

Khiaosa-Ard, R., M. Kreuzer, and F. Leiber. 2015. Apparent recovery of C18 polyunsaturated fatty acids from feed in cow milk: A meta-analysis of the importance of dietary fatty acids and feeding regimens in diets without fat supplementation. J. Dairy Sci. 98:6399-6414. https://doi.org/10.3168/jds.2015-9459.
Loor, J. J., M. Doreau, J. M. Chardigny, A. Ollier, J. L. Sebedio, and Y. Chilliard. 2005. Effects of ruminal or duodenal supply of fish oil on milk fat secretion and profiles of trans-fatty acids and conjugated linoleic acid isomers in dairy cows fed maize silage. Anim. Feed Sci. Technol. 119:227-246.

Loor, J. J., K. Ueda, A. Ferlay, Y. Chilliard, and M. Doreau. 2004. Biohydrogenation, duodenal flow, and intestinal digestibility of trans fatty acids and conjugated linoleic acids in response to dietary forage:concentrate ratio and linseed oil in dairy cows. J. Dairy Sci. 87:2472-2485.

Massart-Leen, A. M., E. Roets, G. Peeters, and R. Verbeke. 1983 Propionate for fatty acid synthesis by the mammary gland of the lactating goat. J. Dairy Sci. 66:1445-1454.

Meignan, T., C. Lechartier, G. Chesneau, and N. Bareille. 2017. Effects of feeding extruded linseed on production performance and milk fatty acid profile in dairy cows: A meta-analysis. J. Dairy Sci. 100:4394-4408

Prado, L. A., A. Ferlay, P. Nozière, and P. Schmidely. 2018. Predicting duodenal flows and absorption of fatty acids from dietary characteristics in ruminants: A meta-analysis approach. Animal 14:1-13. https://doi.org/10.1017/S1751731118001982

Schmidely, P., A. Ferlay, G. Maxin, C. Hurtaud, and J. L. Peyraud. 2018. Chapter 11. Milk fat content and composition. Pages 185191 in INRA Feeding System for Ruminants. P. Nozière, D. Sauvant, and L. Delaby, ed. Wageningen Academic Publishers, Wageningen, the Netherlands.

Schmidely, P., F. Glasser, M. Doreau, and D. Sauvant. 2008. Digestion of fatty acids in ruminants: A meta-analysis of flows and variation factors. 1. Total fatty acids. Animal 2:677-690.

Shingfield, K. J., L. Bernard, C. Leroux, and Y. Chilliard. 2010. Role of trans fatty acids in the nutritional regulation of mammary lipogenesis in ruminants. Animal 4:1140-1166.

Shingfield, K. J., J. Rouel, and Y. Chilliard. 2009. Effect of calcium salts of a mixture of conjugated linoleic acids containing trans-10, c-12 in the diet on milk fat synthesis in goats. Br. J. Nutr. 101:1006-1019.

Stamey Lanier, J., J. K. Suagee, O. Becvar, and B. A. Corl. 2013. Mammary uptake of fatty acids supplied by intravenous triacylglycerol infusion to lactating dairy cows. Lipids 48:469-479.

Sterk, A., B. Vlaeminck, A. M. van Vuuren, W. H. Hendriks, and J. Dijkstra. 2012. Effects of feeding different linseed sources on omasal fatty acid flows and fatty acid profiles of plasma and milk fat in lactating dairy cows. J. Dairy Sci. 95:3149-3165.

Toral, P. G., Y. Chilliard, and L. Bernard. 2012. Short communication: In vivo deposition of $\left[1-{ }^{13} \mathrm{C}\right]$ vaccenic acid and the product of its $\Delta^{9}$ desaturation, $\left[1-{ }^{13} \mathrm{C}\right]$ rumenic acid, in the body tissues of lactating goats fed oils. J. Dairy Sci. 95:6755-6759.

Toral, P. G., P. Frutos, D. Carreño, and G. Hervás. 2017. Endogenous synthesis of milk oleic acid in dairy ewes: In vivo measurement using 13C-labeled stearic acid. J. Dairy Sci. 100:5880-5887.

Vahmani, P., K. E. Glover, and A. H. Fredeen. 2014. Effects of pasture versus confinement and marine oil supplementation on the expression of genes involved in lipid metabolism in mammary, liver, and adipose tissues of lactating dairy cows. J. Dairy Sci. 97:4174-4183.

Vlaeminck, B., C. Dufour, A. M. van Vuuren, A. R. J. Cabrita, R. J. Dewhurst, D. Demeyer, and V. Fievez. 2005. Use of odd and branched-chain fatty acids in rumen contents and milk as a potential microbial marker. J. Dairy Sci. 88:1031-1042.

Vlaeminck, B., V. Fievez, A. R. J. Cabrita, A. J. M. Fonseca, and R. J. Dewhurst. 2006. Factors affecting odd- and branched-chain fatty acids in milk: A review. Anim. Feed Sci. Technol. 131:389-417.

Vlaeminck, B., R. Gervais, M. M. Rahman, F. Gadeyne, M. Gorniak, M. Doreau, and V. Fievez. 2015. Postruminal synthesis modifies the odd- and branched-chain fatty acid profile from the duodenum to milk. J. Dairy Sci. 98:4829-4840. 